HETEROCYCLES, Vol. 86, No. 1, 2012, pp. 11 - 67. @ 2012 The Japan Institute of Heterocyclic Chemistry DOI: $10.3987 / C O M-12-S(N)$ Publications

\title{
LIST OF PUBLICATIONS BY EI-ICHI NEGISHI
}

December, 2011

1. Basic Cleavages of Arylsulfonamides.

E. Negishi and A. R. Day, J. Org. Chem., 1965, 30, 43-48.

2. The Carbonylation of Thexyldialkylboranes. A New General Synthesis of Ketones.

H. C. Brown and E. Negishi, J. Am. Chem. Soc., 1967, 89, 5285-5287.

3. Carbonylation of the Organoboranes from the Cyclic Hydroboration of Dienes with Thexylborane. A Simple Procedure the Conversion of Dienes into Cyclic Ketones.

H. C. Brown and E. Negishi, J. Am. Chem. Soc., 1967, 89, 5477-5478.

4. Carbonylation of Perhydro-9b-boraphenalene to Form Perhydro-9b-phenalenol. A New General Synthesis of Polycyclic Derivatives.

H. C. Brown and E. Negishi, J. Am. Chem. Soc., 1967, 89, 5478-5480.

5. A General Stereospecific Annelation for the Synthesis of trans-Fused Polycyclic Ketones via Hydroboration-Carbonylation

H. C. Brown and E. Negishi, Chem. Commun., 1968, 594-595.

6. Conversion of Linear Trienes into Bicyclic Boranes via Hydroboration-Isomerization and Their Carbonylation. A Simple Synthesis of Angularly Substituted Bicyclic Alcohols

H. C. Brown and E. Negishi, J. Am. Chem. Soc., 1969, 91, 1224-1226.

7. Reaction of Cyclic Organoboranes from Dienes with Methyl Vinyl Ketone. A Convenient Synthesis of $\omega$-Hydroxy-ketones from Dienes via Hydroboration.

A. Suzuki, S. Nozawa M. Itoh, H. C. Brown, E. Negishi, and S. K. Gupta, Chem. Commun., 1969, 1009-1010.

8. Organoboranes. IX. Structure of the Organoboranes Formed in the Reaction of 1,3-Butadiene and 
Diborane in the Stoichiometric Ratio. An Unusual Thermal Isomerization of the Organoboranes. H. C. Brown, E. Negishi, and S. K. Gupta, J. Am. Chem. Soc., 1970, 92, 2460-2467.

9. The Reaction of B-Methoxydialkylboranes with Lithium Aluminum Hydride in the Presence of Olefins. A New and General Synthesis of Acyclic and Cyclic Mixed Trialkylboranes and Their Conversion into the Corresponding Trialkylcarbinols via Carbonylation-Oxidation.

H. C. Brown, E. Negishi, and S. K. Gupta, J. Am. Chem. Soc., 1970, 92, 6648-6649.

10. A Facile Opening of the Borolane Ring with Borane. A Simple Entry into 12-Tetramethylenediboranes.

H. C. Brown, E. Negishi, and P. L. Burke, J. Am. Chem. Soc., 1970, 92, 6649-6651.

11. A Simple Synthesis of Bisborinane and Its Applicability in Hydroboration for the Preparation of B-Alkylborinanes.

H. C. Brown and E. Negishi, J. Organometal. Chem., 1971, 26, C67-C69.

12. A Simple Synthesis of Bis(3,5-dimethyl)borinane and Bis(3,6-dimethyl)borepane as New Valuable Reagents via Cyclic Hydroboration.

H. C. Brown and E. Negishi, J. Organometal. Chem., 1971, 28, C1-C4.

13. A New Four-Carbon-Atom Homologation Involving the Free Radical Chain Reaction of 1,3-Butadiene Monoxide with Organoboranes. Synthesis of 4-Alkyl-2-buten-1-ols from Olefins via Hydroboration.

A. Suzuki, N. Miyaura, M. Itoh, H. C. Brown, G. W. Holland, and E. Negishi, J. Am. Chem. Soc., 1971, 93, 2792-2793.

14. Organoboranes, XII. Hydroboration of 1,3-Butadiene with Borane in Tetrahydrofuran in a Ratio Equal to or Smaller than 1:1. Interconversion Between B-Alkylborolane and 1,2-Tetramethylenediboranes.

H. C. Brown, E. Negishi, and P. L. Burke, J. Am. Chem. Soc., 1971, 93, 3400-3409.

15. The Facile Reaction of B-Alkylboracyclanes with $\alpha, \beta$-Unsaturated Carbonyl Derivatives. A Convenient Procedure for the Transfer of Secondary and Tertiary Alkyl Groups from Boron to Carbon in the 1,4-Addition Reaction. 
H. C. Brown and E. Negishi, J. Am. Chem. Soc., 1971, 93, 3777-3779.

16. Bisborolane. A Highly Elusive Bisboracyclane.

H. C. Brown and E. Negishi, J. Am. Chem. Soc., 1971, 93, 6682-6683.

17. The Cyclic Hydroboration of Dienes. A Simple Convenient Route to Heterocyclic Organoboranes. H. C. Brown and E. Negishi, Pure Appl. Chem., 1972, 29, 527-545.

18. A General Multi-Carbon Homologation of Olefins via Hydroboration-Carbonylation. E. Negishi and H. C. Brown, Synthesis, 1972, 196-197.

19. The Reaction of Organoboranes Containing a Tertiary Alkyl Group with Carbon Monoxide. A New Approach to the Synthesis of Highly Branched Trialkylcarbinols.

E. Negishi and H. C. Brown, Synthesis, 1972, 197-199.

20. Hydroboration. XXXI. The Cyclic Hydroboration of Dienes with Borane in Tetrahydrofuran in the Molar Ratio of 1:1.

H. C. Brown, E. Negishi, and P. L. Burke, J. Am. Chem. Soc., 1972, 94, 3561-3567.

21. Hydroboration. XXXII. The Cyclic Hydroboration of Dienes with Thexylboranes. H. C. Brown and E. Negishi, J. Am. Chem. Soc., 1972, 94, 3567-3572.

22. Monomeric Dialkylboranes.

E. Negishi, J.-J. Katz, and H. C. Brown, J. Am. Chem. Soc., 1972, 94, 4025-4027.

23. Remarkably Facile and Selective Dehydroboration of Tetramethylethylene from Thexylmonoalkylboranes under the Influence of Triethylamine. A Novel, Convenient Synthesis of Monoalkylboranes in Trielethylaminates.

H. C. Brown, E. Negishi, and J.-J. Katz, J. Am. Chem. Soc., 1972, 94, 5893-5894.

24. Hydroboration. XXXIII. The Cyclic Hydroboration of 1,4-Pentadiene with Borane in Tetrahydrofuran. Thermal Behavior of the Organoborane Derivatives and a Simple Synthesis of Bisborinane and B-Alkylborinanes.

E. Negishi, P. L. Burke, and H. C. Brown, J. Am. Chem. Soc., 1972, 94, 7431-7437. 
25. An Improved Procedure for the Stereoselective Synthesis of trans Olefins via Hydroboration-Protonolysis.

E. Negishi, J.-J. Katz, and H. C. Brown Negishi, Synthesis, 1972, 555-556.

26. Hydroboration. XXXIV. The Cyclic Hydroboration of 1,5-Hexadiene with Borane in Tetrahydrofuran and 9-Borabicyclo(3.3.1)nonane. A New Convenient Route to the Borepane Ring System Utilizing 9-Borabicyclo(3.3.1)nonane.

P. L. Burke, E. Negishi, and H. C. Brown, J. Am. Chem. Soc., 1973, 95, 3654-3662.

27. A Stereoselective Synthesis of Conjugated trans, trans-Dienes and trans-Alkenyl Ketones via Hydroboration.

E. Negishi and T. Yoshida, Chem. Commun., 1973, 606-607.

28. Hydroboration. XXXV. The Cyclic Hydroboration of 2,4-Dimethyl-1,4-pentadiene and 2,5-Dimethyl-1,5-hexadiene. A Simple Synthesis of Bis(3,5-dimethyl)borinane and Bis(3,6-dimethyl)borepane and Their Application to the 1,4-Addition Reaction of Organoboranes.

E. Negishi and H. C. Brown, J. Am. Chem. Soc., 1973, 95, 6757-6763.

29. An Intramolecular Michael Reaction Involving Borate Complexes. A Novel Synthesis of $\beta$-Hydroxycarboxyic Acids.

E. Negishi and T. Yoshida, J. Am. Chem. Soc., 1973, 95, 6837-6838.

30. A Highly Stereoselective Synthesis of Conjugated trans-Enynes Readily Convertible into Conjugated cis, trans-Dienes and its Application to the Synthesis of the Pheromone Bombykol.

E. Negishi, G. Lew, and T. Yoshida, Chem. Commun., 1973, 874-875.

31. Carbonylation of Organoboranes.

E. Negishi, Intra-Science Chem. Reports, 1973, 7, 81-94.

32. Thexylborane-A Highly Versatile Reagent in Organic Synthesis via Hydroboration.

E. Negishi and H. C. Brown, Synthesis, 1974, 77-89.

33. A Stereoselective Synthesis of trans-1,4-Dialkyl-1,2,3-butatrienes via Hydroboration.

T. Yoshida, R. M. Williams, and E. Negishi, J. Am. Chem. Soc., 1974, 96, 3688-3690. 
34. A Novel Stereoselective Synthesis of $(E)$ and $(Z)-\alpha, \beta$-Unsaturated Carboxylic Esters via Hydroboration.

E. Negishi, G. Lew, and T. Yoshida, J. Org. Chem., 1974, 39, 2321-2322.

35. A Novel Copper-Containing Hydride Species and its Application to the Reduction of Organic Compounds.

T. Yoshida and E. Negishi, Chem. Commun., 1974, 762-763.

36. Novel and Regioselective Aromatic Double Substitution Involving Borate Anions and a Regio- and Stereoselective Route to Dihydroaromatic Derivatives.

E. Negishi and R. E. Merrill, J. Am. Chem. Soc., 1974, 96, 860-861.

37. Tetrahydrofuran-Promoted Aryl-Alkyl Coupling Involving Organolithium Reagents.

R. E. Merrill and E. Negishi, J. Org. Chem., 1974, 39, 3452-3453.

38. A Novel Regio- and Chemoselective Aryl Ketone Synthesis by the Reaction of Arylborate Anions with Aryl Chlorides.

E. Negishi, A. Abramovitch, and R. E. Merrill, J. Am. Chem. Soc., 1975, 97, 138-139.

39. A General One-Carbon Homologation of Organoboranes via $\alpha$-Thioorganoborate Anions.

E. Negishi, T. Yoshida, A. Silveira, Jr., and B. L. Chiou, J. Org. Chem., 1975, 40, 814-816.

40. Organoboranes and Organoborate Anions - New Classes of Electrophiles and Nucleophiles in Organic Synthesis.

E. Negishi, J. Chem. Educ., 1975, 52, 159-165.

41. Hydroboration. XXXVII. The Structural Study of the Hydroboration of Olefins with Thexylborane. A Simple Synthesis of Thexylmonoalkylboranes.

H. C. Brown, E. Negishi, and J.-J. Katz, J. Am. Chem. Soc., 1975, 97, 2791-2798.

42. Hydroboration. XXXVIII. The Structural Study of the Hydroboration of Olefins with Thexylmonoalkylboranes. A Convenient Route to Thexyldialkylboranes, "Mixed" Dialkyl-boranes and "Mixed" Trialkylboranes.

H. C. Brown, J.-J. Katz, C. F. Lanes, and E. Negishi, J. Am. Chem. Soc., 1975, 97, 2799-2804. 
43. An Intermolecular Alkyl-Transfer Reaction of Tetraalkylborate Anions with Acyl Halides. A Novel Method for Moderating the Carbanion Reactivity.

E. Negishi, T. Yoshida, and K. W. Chiu, J. Org. Chem., 1975, 40, 1676-1677.

44. A Convenient Synthesis of cis-Alkenylboranes and its Application to the Synthesis of Disubstituted trans-Alkenes and Conjugated cis-Enynes.

E. Negishi, R. M. Williams, G. Lew, and T. Yoshida, J. Organometal. Chem., 1975, 92, C4-C6.

45. A Convenient Method for the Tertiary Alkyl-Alkynyl Coupling via Organoalanes.

E. Negishi and S. Baba, J. Am. Chem. Soc., 1975, 97, 7385-7387.

46. Stereoselective Synthesis of $\beta$-Hydroxy Substituted trans-Alkenes by the Reaction of trans-Alkenyltrialkylaluminates with Epoxides.

E. Negishi, S. Baba, and A. O. King, J. Chem. Soc. Chem. Commun., 1976, 17-18.

47. Preparation of Secondary Alcohols by Reaction of Trialkylboranes with Bis(phenylthio)methyllithium.

R. J. Hughes, A. Pelter, K. Smith, E. Negishi, and T. Yoshida, Tetrahedron Lett., 1976, 87-88.

48. Chemistry of Organoborates.

E. Negishi, J. Organometal., 1976, 108, 281-324.

49. A Simple Synthesis of Juvabione and Todomatuic Acid via Hydroboration-Carbonylation.

E. Negishi, M. Sabanski, J.-J. Katz, and H. C. Brown, Tetrahedron, 1976, 32, 925-926.

50. An Unusually Facile Dehydroboration of Triorganoboranes Formed by Treatment of Alkenyltrialkylborates with Hydrochloric Acid.

K. W. Chiu, E. Negishi, M. S. Plante, and A. Silveira, Jr., Organometal. Chem., 1976, 112, C3-C6.

51. A Stereoselective Synthesis of Disubstituted trans-Alkenes by the Reaction of trans-Alkenyltrialkylaluminates with Alkyl Halides and Sulfonates.

S. Baba, D. E. Van Horn, and E. Negishi, Tetrahedron Lett., 1976, 1927-1930.

52. A New Mild Procedure for the Protonolysis of Alkenylboron Derivatives via Treatment of 

Alkenyltrialkylborates with Aqueous Bases.
E. Negishi and K. W. Chiu, J. Org. Chem., 1976, 41, 3484-3486.

53. Organoboron and Organoaluminum Compounds as Unique Nucleophiles in Organic Synthesis.

E. Negishi, "New Applications of Organometallics Reagents in Organic Synthesis," D. Seyferth, Ed., Elsevier, Amsterdam, 1976, pp. 93-125.

54. Novel Stereoselective Alkenyl-Aryl Coupling via Nickel-Catalyzed Reaction of Alkenylalanes with Aryl Halides.

E. Negishi and S. Baba, J. Chem. Soc. Chem. Comm., 1976, 596-597.

55. A Novel Stereospecific Alkenyl-Alkenyl Cross-Coupling of a Palladium- or Nickel-Catalyzed Reaction of Alkenylalanes with Alkenyl Halides.

S. Baba and E. Negishi, J. Am. Chem. Soc., 1976, 98, 6729-6731.

56. Organoborane Heterocycles via Cyclic Hydroboration of Dienes.

E. Negishi, S. U. Kulkarni, and H. C. Brown, Heterocycles, 1976, 5, 883-904.

57. A Highly Efficient Chemo-, Regio-, and Stereoselective Synthesis of (7E,9E)-Dodecadien-1-yl Acetate. A Sex Pheromone of Lobesia botrana, via A Functionalized Organoborate.

E. Negishi and A. Abramovitch, Tetrahedron Lett., 1977, 411-414.

58. Novel Borate Anion-Assisted Cyclization. Facile Rearrangement of 1-Cyclopropylidenealkylboranes to Homopropargylboranes.

R. E. Merrill, J. L. Allen, A. Abramovitch, and E. Negishi, Tetrahedron Lett., 1977, 1019-1022.

59. Selective Carbon-Carbon Bond Formation via Transition Metal Catalysis. 3. A Highly Selective Synthesis of Unsymmetrical Biaryls and Diarylmethanes by the Nickel- or Palladium-Catalyzed Reaction of Aryl- and Benzylzinc Derivatives with Aryl Halides.

E. Negishi, A. O. King, and N. Okudado, J. Org. Chem., 1977, 42, 1821-1823.

60. Selective Carbon-Carbon Bond Formation via Transition Metal Catalysis. 4. A Novel Approach to Cross-Coupling Exemplified by the Ni-Catalyzed Reaction of Alkenylzirconium Derivatives with Aryl Halides. 
E. Negishi and D. E. Van Horn, J. Am. Chem. Soc., 1977, 99, 3168-3170.

61. A Novel Synthesis of an $\omega$-Alkynylorganometallic Reagent via Triple Bond Isomerization with Potassium 3-Aminopropylamide: $\omega$-Alkynylorganometallic Reagent via Riple Bond Isomerization with Potassium 3-Aminopropylamide: $\omega$-(9-Borabicycl(3.3.1) nonyl)-1-Alkynes.

C. A. Brown and E. Negishi, J. Chem. Soc. Chem. Comm., 1977, 318-319.

62. Synthesis of Secondary or Tertiary Alcohols by Reactions of Trialkylboranes with Acyl Carbanion Equivalents.

R. J. Hughes, S. Ncube, A. Pelter, K. Smith, E. Negishi, and T. Yoshida, J. Chem. Soc., Perkin Trans. I, 1977, 1172-1176.

63. Boraheterocycles via Cyclic Hydroboration

H. C. Brown and E. Negishi, Tetrahedron, 1977, 33, 2331-2357.

64. Highly General Stereo-, Regio- and Chemoselective Synthesis of Terminal and Internal Conjugated Enynes by the Pd-Catalyzed Reactions of Alkynylzinc Reagents with Alkenyl Halides.

A. O. King, N. Okukado, and E. Negishi, J. Chem. Soc. Chem. Commun., 1977, 683-684.

65. A General Synthesis of Terminal and Internal Arylalkynes by the Pd-Catalyzed Reaction of Alkynylzinc Reagents with Aryl Halides.

A. O. King, E. Negishi, F. J. Villani, Jr., and A. Silveira, Jr., J. Org. Chem., 1978, 43, 358-360.

66. A Highly Stereo-, Regio-, and Chemoselective Synthesis of Conjugated Dienes by the Palladium-Catalyzed Reaction of (E)-1-Alkenylzirconium Derivatives with Alkenyl Halides.

N. Okukado, D. E. Van Horn, W. L. Klima, and E. Negishi, Tetrahedron Lett., 1978, 1027-1030.

67. Controlled Carbometallation. The Reaction of Acetylenes with Organoalane-Zirconocene Dichlorides Complexes as a Route to Stereo- and Regio-Defined Trisubstituted Olefins.

E. E. Van Horn and E. Negishi, J. Am. Chem. Soc., 1978, 100, 2252-2254.

68. Double and Multiple Catalysis in the Cross-Coupling Reaction and Its Application to the Stereoand Regioselective Synthesis of Trisubstituted Olefins.

E. Negishi, N. Okukado, A. O. King, D. E. Van Horn, and B. I. Spiegel, J. Am. Chem. Soc., 1978, 
100, 2254-2256.

69. Controlled Carbometallation. II. The Addition Reaction of Trimethylalane-Titanocene Dichloride with Acetylenes.

E. E. Van Horn, L. F. Valente, M. J. Idacavage, and E. Negishi, J. Organometal. Chem., 1978, 156, C20-C24.

70. One-Step Conversion of Terminal Acetylenes into Terminally Functionalized. (E)-3-Methyl-2alkenes via Zirconium-Catalyzed Carboalumination. A Simple and Selective route to Terpenoids. N. Okukado and E. Negishi, Tetrahedron Lett., 1978, 2357-2360.

71. Scope of the Reaction of Organoborates with Organolithiums as a Method of Preparation of Lithium Organoborates. Stability of Lithium Organoborates.

E. Negishi, M. J. Idacavage, K. W. Chiu, T. Yoshida, A. Abramovitch, M. E. Goettel, A. Silveira, Jr., and H. D. Bretherick, J. Chem. Soc., Perkin Trans. 2., 1978, 1225-1232.

72. Selective Carbon-Carbon Bond Formation via Transition Metal Catalysis: Is Nickel or Palladium Better than Copper?

E. Negishi, "Aspects of Mechanism and Organometallic Chemistry," J. H. Brewster, ed., Plenum Press, New York, 1978, p. 285-317.

73. A Highly Selective Method for $\alpha$-Alkylation of Ketones via Potassium Enoxytrialkylborates.

E. Negishi, M. J. Idacavage, F. DiPasquale, and A. Silveira, Jr., Tetrahedron Lett., 1979, 845-848.

74. A Stereo- and Regioselective Synthesis of (E)- $\beta$-Methylalkenyl Iodides via Zirconium-Catalyzed Carboalumination of Terminal Acetylenes.

E. Negishi, D. E. Van Horn, A. O. King, and N. Okukado, Synthesis Stuttgart, 1979, 501-502.

75. NMR Determination of $n$-Butyllithium.

A. Silveira, Jr., H. D. Bretherick, Jr., and E. Negishi, J. Chem. Educ., 1979, 56, 560.

76. Palladium-Catalyzed Acetylene Syntheses.

E. Negishi, Preprints Petroleum Div. ACS, 1979, 24, 226-232. 
77. Perhydro-9b-boraphenalene and Perhydro-9b-phenalenol.

E. Negishi and H. C. Brown, Org. Synth, 1983, 61, 103-111.

78. "Organometallics in Organic Synthesis," Vol. 1, General Discussions and Organometallics of Main Group Metals in Organic Synthesis.

E. Negishi, Wiley-Interscience, 1980, 532 pp.

79. Remarkable Countercation Effect in the Reaction of Organoborates with Enolates.

M. J. Idacavage, E. Negishi, and C. A. Brown, J. Organometal. Chem., 1980, 186, C55-C57.

80. Conversion of Methyl Ketones into Terminal Acetylenes and (E)-Trisubstituted Olefins of Terpenoid Origin.

E. Negishi, A. O. King, W. P. Klima, W. Patterson, and A. Silveira, Jr., J. Org. Chem., 1980, 45, 2526-2528.

81. Palladium-Catalyzed Cross-Coupling Reaction of Homoallylic or Homopropargylic Organozincs with Alkenyl Halides as a New Selective Route to 1,5-Dienes and 1,5-Enynes.

E. Negishi, L. F. Valente, and M. Kobayashi, J. Am. Chem. Soc., 1980, 102, 3298-3299.

82. A Novel Zirconium-Catalzyed Hydroalumination of Olefins.

E. Negishi and T. Yoshida, Tetrahedron Lett., 1980, 1501-1504.

83. A Selective and Efficient Synthesis of (E)-4-Methyl-3-alken-1-ols via Zirconium Catal yzed Carboalumination of Terminal Alkynes.

M. Kobayashi, L. F. Valente, E. Negishi, W. Patterson, and A. Silveira, Jr., Synthesis, 1980, 1034-1035.

84. A Pd-Catalyzed Stereospecific Substitution Reaction of Homoallylzincs with $\beta$-Bromo-Substituted $\alpha, \beta$-Unsaturated Carbonyl Derivatives as a Novel Route to Butenoilides and Related Natural Products of Terpenoid Origin. A Highly Selective Synthesis of Mokupalide.

M. Kobayashi and E. Negishi, J. Org. Chem., 1980, 45, 5223-5225.

85. 1,1-Dimetalloalkenes Containing Aluminum as Well as Titanium or Zirconium. Their Structures and Use as Novel Alkenylidene and Alkenyl Transfer Agents. 
T. Yoshida and E. Negishi, J. Am. Chem. Soc., 1981, 103, 1276-1277.

86. Palladium-Catalyzed Stereo- and Regiospecific Coupling of Allylic Derivatives with Alkenyl and Arylmetals. A Highly Selective Synthesis of 1,4-Dienes.

H. Matsushita and E. Negishi, J. Am. Chem. Soc., 1981, 103, 2882-2884.

87. A Versatile and Selective Route to Difunctional Trisubstituted (E)-Alkene Synthons via Zirconium-Catalyzed Carboalumination of Alkynes.

C. L. Rand, D. E. Van Horn, M. W. Moore, and E. Negishi, J. Org. Chem., 1981, 46, 4093-4096.

88. Highly Selected Synthesis of Allylated Arenes and Diarylmethanes via Palladium-Catalyzed Cross Coupling Involving Benzylic Derivatives.

E. Negishi, H. Matsushita, and N. Okukado, Tetrahedron Lett., 1981, 22, 2715-2718.

89. Mechanism of the Zr-Catalyzed Carboalumination of Alkynes. Evidence for Direct Carboalumination.

E. Negishi and T. Yoshida, J. Am. Chem. Soc., 1981, 103, 4985-4987.

90. Scope of the Palladium-Catalyzed Coupling Reaction of Organometallics with Allylic Electrophiles. Effect of the Leaving Group.

E. Negishi, S. Chatterjee, and H. Matsushita, Tetrahedron Lett., 1981, 22, 3737-3740.

91. Bimetallic Catalytic Systems Containing Ti, Zr, Ni, and Pd. Their Applications to Selective Organic Syntheses.

E. Negishi, Pure Appl. Chem., 1981, 53, 2333-2356.

92. Highly Sensitive and Convenient Method for the Synthesis of 1,5-Enynes and 1,5-Dienes by the Reaction of 1,3-Dilithiopropargyl Phenyl Sulfide with Allylic Halides.

E. Negishi, C. L. Rand, and K. P. Jadhav, J. Org. Chem., 1981, 46, 5041-5044.

93. Anti Stereospecificity in the Palladium-Catalyzed Reactions of Alkenylalanes with Allylic Electrophiles and Its Mechanistic Implication.

H. Matsushita and E. Negishi, J. Chem. Soc. Chem. Commun., 1982, 160-161. 
94. Stereo- and Regioselective Routes to Allylic Silanes.

E. Negishi, F.-T. Luo, and C. L. Rand, Tetrahedron Lett., 1982, 23, 27-30.

95. A Regiospecific Synthesis of Carbosubstituted Heteroaromatic Derivatives via Pd-Catalyzed Cross Coupling.

E. Negishi, F.-T. Luo, R. Frisbee, and H. Matsushita, Heterocycles, 1982, 18, 117-122.

96. A Selective Synthesis of Alkenylmercuric Chlorides via Alkenylalanes.

E. Negishi, K. P. Jadhav, and N. Daotien, Tetrahedron Lett., 1982, 23, 2085-2086.

97. Selective and Convenient Synthesis of $\beta, \beta$-Disubstituted Alkenylmetals Containing Boron and Zirconium via Carboalumination of Alkynes.

E. Negishi and L. D. Boardman, Tetrahedron Lett., 1982, 23, 3327-3330.

98. A Highly Regio- and Stereospecific Palladium-Catalyzed Allylation of Enolates Derived from Ketones.

E. Negishi, H. Matsushita, S. Chatterjee, and R. A. John, J. Org. Chem., 1982, 47, 3188-3190.

99. Bimetallic Reagent Systems Containing a Main Group Metal and a Transition Metal (in Japanese). E. Negishi, Kagaku Zokan (in Japanese) No. 96, pp. 49-61, H. Nozaki, T. Mukaiyama, and H. Yamamoto, eds. Kagaku Dojin, Kyoto, 1982.

100. Palladium- or Nickel-Catalyzed Cross Coupling. A New Selective Method for Carbon-Carbon Bond Formation.

E. Negishi, Acc. Chem. Res., 1982, 15, 340-348.

101. General Discussions of the Organoboron Reactions.

E. Negishi, "Comprehensive Organometallic Chemistry", G. T. Wilkinson, F. G. A. Stone, and E. W. Abel, Eds. Pergamon, Chap. 45.6, pp. 279-288, 1982.

102. Aliphatic Organoboron Compounds.

E. Negishi, "Comprehensive Organometallic Chemistry", G. T. Wilkinson, F. G. A. Stone, and E. W. Abel, Eds. Pergamon, Chap. 45.7, pp. 289-329, 1982. 
103. Alkenylboron Compounds.

E. Negishi, "Comprehensive Organometallic Chemistry", G. T. Wilkinson, F. G. A. Stone, and E. W. Abel, Eds. Pergamon, Chap. 45.8, pp. 331-352, 1982.

104. Arylboron Compounds.

E. Negishi, "Comprehensive Organometallic Chemistry", G. T. Wilkinson, F. G. A. Stone, and E. W. Abel, Eds. Pergamon, Chap. 45.9, pp. 353-368, 1982.

105. Alkynylboron Compounds.

E. Negishi, "Comprehensive Organometallic Chemistry", G. T. Wilkinson, F. G. A. Stone, and E. W. Abel, Eds. Pergamon, Chap. 45.10, pp. 369-380, 1982.

106. Miscellaneous Organoboron Compounds.

E. Negishi, "Comprehensive Organometallic Chemistry", G. T. Wilkinson, F. G. A. Stone, and E. W. Abel, Eds. Pergamon, Chap. 45.11, pp. 381-396, 1982.

107. Palladium-Catalyzed Reactions of Allylic Electrophiles with Organo-metallic Reagents. A Regioselective 1,4-Elimination and Regio- and Stereoselective Reduction of Allylic Derivatives. E. Matsushita and E. Negishi, J. Org. Chem., 1982, 47, 4161-4165.

108. Biomimetic Polyene Cyclization Producing Medium- and Large-Ring Natural Products (in Japanese).

E. Negishi, Kagaku Zokan (in Japanese) No. 99, p. 115-123, H. Nozaki ed. Kagaku Dojin, Kyoto, 1983.

109. Controlled Carbometallation. 15. Zirconium-Promoted Carbozincation of Alkynes.

E. Negishi, D. E. Van Horn, T. Yoshida, and C. L. Rand, Organometallics, 1983, 2, 563-565.

110. 1,4- and 1,5-Diketones via Palladium-Catalyzed Allylation of Potassium Enoxyborates.

E. Negishi, F. T. Luo, A. J. Pecora, and A. Silveira, Jr., J. Org. Chem., 1983, 48, 2427-2429.

111. Highly Regioselective Generation of "Thermodynamic" Enolates and Their Direct Characterization by NMR.

E. Negishi and S. Chatterjee, Tetrahedron Lett., 1983, 24, 1341-1344. 
112. Palladium-Catalyzed Cross-Coupling Reaction of $\alpha$-Heterosubstituted Alkenylmetals. Stereoselective Route to Heterosubstituted Dienes Suitable for the Diels-Alder Reaction. E. Negishi and F. T. Luo, J. Org. Chem., 1983, 48, 1560-1562.

113. Countercation Effects on the Palladium-Catalyzed Allylation of Enolates.

E. Negishi and R. A. John, J. Org. Chem., 1983, 48, 4098-4102.

114. Palladium- or Nickel-Catalyzed Cross Coupling Involving Proximally Heterofunctional Reagents. E. Negishi, "Current Trends in Organo Synthesis", H. Nozaki, ed., Pergamon, 1983, pp. 269-280.

115. A Convenient Synthesis of Unsymmetrical Bibenzyls, Homoallylarenes, and Homopropargylarenes via Palladium-Catalyzed Cross Coupling. E. Negishi, H. Matsushita, M. Kobayashi, and C. L. Rand, Tetrahedron Lett., 1983, 24, 3823-3824.

116. Novel Silicon-Promoted Cyclialkylation of Alkenylmetal Derivatives. E. Negishi, L. D. Boardman, J. M. Tour, H. Sawada, and C. L. Rand, J. Am. Chem., 1983, 105, 5344-6346.

117. Palladium-Catalyzed Acylation of Organozincs and Other Organometallics as a Convenient Route to Ketones.

E. Negishi, V. Bagheri, S. Chatterjee, F. T. Luo, J. A. Miller, and A. T. Stoll, Tetrahedron Lett., 1983, 24, 5181-5184.

118. Novel Syntheses of Silylcyclopentene Derivatives via Regio- and Stereo-selective Allylzincation of Alkynes.

E. Negishi and J. A. Miller, J. Am. Chem. Soc., 1983, 105, 6761-6763.

119. A Highly Selective Synthesis of $\alpha$-Alkylidenetetrahydrofurans and $\gamma$-Alkylidenebutyrolactones via Intramolecular Opening of Epoxysilanes

F. T. Luo and E. Negishi, J. Org. Chem., 1983, 48, 5144-5146.

120. Cyclic Carboalumination of Alkynylsilanes Forming Exocyclic Alkenes.

J. A. Miller and E. Negishi, Israel J. Chem., 1984, 24, 76-81. 
121. A General Method for the Preparation of Terminal and Internal Conjugated Diynes via the Palladium Catalyzed Cross Coupling.

E. Negishi, N. Okukado, S. F. Lovich, and F. T. Luo, J. Org. Chem., 1984, 49, 2629-2632.

122. Reaction of Alkenes and Dienes with $t$-Butylmagnesium Halides and Zirconoene Dihalides. A Convenient Procedure for Hydrozirconation and a Novel $t$-Butylzirconation of Conjugated Alkenes. E. Negishi, A. J. Miller, and T. Yoshida, Tetrahedron Lett., 1984, 25, 3407-3410.

123. Palladium-Catalyzed Synthesis of 1,4-Dienes by Allylation of Alkenylalanes: $\alpha$-Farnesene. E. Negishi and H. Matsushita, Org. Synth., 1984, 63, 31-38.

124. Mechanistic Duality in Cyclialkylation of Alkenylmetal Derivatives.

L. D. Boardman, V. Bagheri, H. Sawada, and E. Negishi, J. Am. Chem. Soc., 1984, 106, 6105-6107.

125. Zirconium-Catalyzed Allylalumination and Benzylalumination of Alkynes.

J. A. Miller and E. Negishi, Tetrahedron Lett., 1984, 25, 5863-586

126. Formation of Carbon-Carbon and Carbon-Hetero Atom Bonds via Organo-boranes and Organoborates.

E. Negishi and M. J. Idacavage, Org. React., 1985, 33, 1-246.

127. Polycyclic Hydroboration of Acyclic and Cyclic Trienes. Reexamination of the Structures of Perhydro-9b-boraphenalenes.

H. C. Brown, E. Negishi, and W. C. Dickason, J. Org. Chem., 1985, 50, 520-527.

128. Palladium-Catalyzed Cyclization via Intramolecular Allylation of Alkenylmetals.

S. Chatterjee and E. Negishi, J. Organometal Chem., 1985, 285, C1-C4.

129. Palladium-Catalyzed Reaction of Organometals with Allylic Acetals and Orthoesters ad Conjugate Addition Equivalents.

S. Chatterjee and E. Negishi, J. Org. Chem., 1985, 50, 3406-3408.

130. Zirconium-Promoted Bicyclization of Enynes.

E. Negishi, S. J. Holmes, J. M. Tour, and J. A. Miller, J. Am. Chem. Soc., 1985, 107, 2568-2569. 
131. Palladium-Catalyzed Allylation of Lithium 3-Alkenyl-1-Cyclopentenolates-Triethylborane and Its Application to a Selective Synthesis of Methyl ( $\underline{Z})$-Jasmonate.

F. T. Luo and E. Negishi, Tetrahedron Lett., 1985, 26, 2177-2180.

132. Organozirconium Compounds as New Reagents and Intermediates.

E. Negishi and T. Takahashi, Aldrichim. Acta, 1985, 18, 31-48.

133. Conversion of Methyl Ketones into Terminal Alkynes. (E)-Buten-3-ynyl-2,6,6-trimethyl-1cyclohexene.

E. Negishi, A. O. King, and J. M. Tour, Org. Synth., 1985, 64, 44-49.

134. Carbometallation Reaction of Alkynes with Organoalane-Zirconocene Derivatives as a Route to Stereo- and Regio-Defined Trisubstituted Alkenes.

E. Negishi, D. E. Van Horn, and T. Yoshida, J. Am. Chem. Soc., 1985, 107, 6639-6647.

135. A Mild and Selective Synthesis of Cyclopropene and Cyclopropane Derivatives via Cycliallylation of Alkenyllithiums.
A. T. Stoll and E. Negishi, Tetrahedron Lett., 1985, 26, 5671-5674.

136. A Selective Synthesis of 11-Deoxyprostaglandin $E_{2}$ Methyl Ester and Its 15-Epimer.

F. T. Luo and E. Negishi, J. Org. Chem., 1985, 50, 4762-4766.

137. Controlled and Catalytic Acylpalladation. A Novel Route to Cyclopentenone and Cyclohexenone Derivatives.

J. M. Tour and E. Negishi, J. Am. Chem. Soc., 1985, 107, 8289-8291.

138. Synthesis of Cyclopentenones and Cyclohexeneones via Cycliacylation of Alkenyllithiums.

H. Sawada, M. B. Webb, A. T. Stoll, and E. Negishi, Tetrahedron Lett., 1986, 27, 775-778.

139. On the Origin of the Configurational Instability of 1-Silyl-1-alkenyllithiums and Related Alkenylmetals.

E. Negishi and T. Takahashi, J. Am. Chem. Soc., 1986, 108, 3402-3408.

140. Reaction of Zirconocene Dichloride with Alkyllithiums or Alkyl Grignard Reagents as a 
Convenient Method for Generating a "Zirconocene" Equivalant and its use in Zirconium-Promoted Cyclization of Alkenes, Alkynes, Dienes, Enynes, and Diynes.

E. Negishi, F. E. Cederbaum, and T. Takahashi, Tetrahedron Lett., 1986, 27, 2829-2832

141. Complete Reversal of Regiochemistry in Cyclic Acylpalladation. Novel Synthesis of Quinones.

E. Negishi and J. M. Tour, Tetrahedron Lett., 1986, 27, 4869-4872.

142. "Bis(triphenylphosphine)palladium": Its Generation, Characterization, and Reactions.

E. Negishi, T. Takahashi, and K. Akiyoshi, J. Chem. Soc., Chem. Commun., 1986, 1338-1339.

143. A Selective Method for the Synthesis of Stereodefined Exocyclic Alkenes via Allylmetallation of Propargyl Alcohols.

E. Negishi, Y. Zhang, F. E. Cederbaum, and M. B. Webb, J. Org. Chem., 1986, 51, 4080-4082.

144. Potassium (2-Methyl-1-cyclohexenyloxy)triethylborate.

E. Negishi and S. Chatterjee, Organometal. Synth., 1986, 3, 453-455.

145. (E)-2-Phenyl-1-propenyldimethylalane via Zirconium-Catalyzed Carboalumination of Phenylethyne. E. Negishi and D. E. Van Horn, Organometal. Synth., 1986, 3, 467-471.

146. (2E)-1-Trimethylsilyl-3,7-dimethyl-2,6-octadiene (Geranyltrimethylsilane)

E. Negishi and F. T. Luo, Organometal. Synth., 1986, 3, 544-546.

147. Vinylic Organoboranes. 6. A General Stereospecific Synthesis of (E)-Disubstituted Alkenes via Hydroboration-Base-Induced Migration-Protonolysis of 1-Halo-1-Alkynes.

H. C. Brown, D. Basavaiah, S. U. Kulkarni, H. D. Lee, E. Negishi, and J.-J. Katz, J. Org. Chem., 1986, 51, 5270-5276.

148. Zirconium-Promoted Enyne Bicyclization. Effects of Enyne Structure.

E. Negishi, D. R. Swanson, F. E. Cederbaum, and T. Takahashi, Tetrahedron Lett., 1987, 28, 917-920.

149. Palladium- or Nickel-Catalyzed Reactions of Alkenylmetals with Unsaturated Organic Halides as a Selective Route to Arylated Alkenes and Con jugated Dienes: Scope, Limitations, and Mechanism. 
E. Negishi, T. Takahashi, S. Baba, D. E. Van Horn, and N. Okukado, J. Am. Chem. Soc., 1987, 109, 2393-2401.

150. Controlled Carbometallation as a New Tool for Carbon-Carbon Bond Formation and Its Application to Cyclization.

E. Negishi, Acc. Chem. Res., 1987, 20, 65-72.

151. Zirconacyclopropanes and Zirconacyclopropenes: Their Synthesis, Characterization, and Reactions. T. Takahashi, D. R. Swanson, and E. Negishi, Chem. Lett., 1987, 623-626.

152. Highly Selective Methods for $\alpha$-Alkenylation and $\alpha$-Arylation of Ketones via Palladium- or Nickel-Catalyzed Alkenyl-Alkenyl Coupling.

E. Negishi and K. Akiyoshi, Chem. Lett., 1987, 1007-1010.

153. Inhibition of Reductive Elimination of Diorganopalladium Species by Formation of Tetraorganopalladates.

E. Negishi, K. Akiyoshi, and T. Takahashi, J. Chem. Soc., Chem. Commun., 1987, 477-478.

154. Palladium-Catalyzed or -Promoted Reductive Carbon-Carbon Coupling. Effects of Phosphines and Carbon Ligands.

E. Negishi, T. Takahashi, and K. Akiyoshi, J. Organomet. Chem., 1987, 334, 181-194.

155. Highly Stereoselective Synthesis of Exocyclic Alkenes via Cyclialkylation.

E. Negishi, Y, Zhang, and V. Bagheri, Tetrahedron Lett., 1987, 28, 5793-5796.

156. Alkylation and Allylation of Lithium Arylborates. Factors Affecting the Di/Mono Substitution Ratio.

E. Negishi, R. E. Merrill, A. Abramovitch, and D. P. Campbell, Bull. Korean Chem. Soc., 1987, 8, 424-425.

157. Palladium-Catalyzed Synthesis of Conjugated Dienes. (5E,7E)- and (5Z,7E)-5,7-Hexadeadienes.

E. Negishi, T. Takahashi, and S. Baba, Org. Synth., 1987, 66, 60-66.

158. 2-Methyl-4'-nitrobiphenyl. Synthesis of Biaryls via Palladium- or Nickel-Catalyzed Cross Coupling. 
E. Negishi, T. Takahashi, and A. O. King, Org. Synth., 1987, 66, 67-74.

159. A Novel Bicyclization Methodology via Cyclialkylation of $\omega$-Halo-1-metallo-1-alkynes Containing Aluminum and Zinc.

E. Negishi, H, Sawada, J. M. Tour, and Y. Wei, J. Org. Chem., 1988, 53, 913-915.

160. Organozirconium Compounds for Organic Synthesis.

E. Negishi and T. Takahashi, Synthesis, 1988, 1, 1-19.

161. Novel 1,2-Migration Reactions of Organometals Containing Aluminum, Zinc, and Other Main Group Metals with $\alpha$-Haloorganolithiums.

E. Negishi and K. Akiyoshi, J. Am. Chem. Soc., 1988, 110, 646-647.

162. One-Pot Conversion of Alkynes and Alkenes into One-Carbon Homologated Aldehydes via Hydrozirconation-Isocyanide Insertion-Hydrolysis.

E. Negishi, D. R. Swanson, and S. R. Miller, Tetrahedron Lett., 1988, 29, 1631-1634.

163. Aspects of Cross-Coupling Reactions Catalyzed by Palladium and Nickel Complexes.

E. Negishi, T. Takahashi, and K. Akiyoshi, "Catalysis of Organic Reactions," P. N. Rylander, H. Greenfield, and R. L. Augustine, Eds., Mercel Dekker, New York, 1988, p. 381-407.

164. Novel Silicon-Promoted Cyclialkylation of $\omega$-Halo-1-alkenylmetals Derivatives. Synthetic Scope and Mechanism.

E. Negishi, L. D. Boardman, H. Sawada, V. Bagheri, A. T. Stoll, J. M. Tour, and C. L. Rand, J. Am. Chem. Soc., 1988, 110, 5383-5396.

165. Efficient Synthesis of Carbobicyclic and Carbopolycyclic Compounds via Intramolecular carbopalladation Catalyzed by Palladium-Phosphine Complex.

E. Negishi, Y. Zhang, and B. O'Connor, Tetrahedron Lett., 1988, 29, 2915-2918.

166. Palladium-Catalyzed Cyclization of Alkenyl and Aryl Halides Containing $\alpha, \beta$-Unsaturated Carbonyl Groups via Intramolecular Carbopalladation.

B. O'Connor, Y. Zhang, E. Negishi, F. T. Luo, and J. W. Cheng, Tetrahedron Lett., 1988, 29, 3903-3906. 
167. Palladium-Catalyzed Procedures for [3+2] Annulation via Intramolecular Alkenyl- and Arylpalladation.

Y. Zhang, B. O'Connor, and E. Negishi, J. Org. Chem., 1988, 53, 5588-5590.

168. Palladium-Catalyzed Cyclic Acylmetallation of Allylic Electrophiles as a Route to Cyclopentene Derivatives.

E. Negishi, G. Wu, and J. M. Tour, Tetrahedron Lett., 1988, 29, 6745-6748.

169. Organometallic Compound.

E. Negishi, 1989 Yearbook of Science and Technology, McGraw-Hill, New York, 1988, pp. 262-267.

170. Synthesis of Benzofurans, Tetrahydrobenzofurans, and Related Cyclic Ethers via Cyclic Carbopalladation.

E. Negishi, T. Nguyen, B. O'Connor, J. M. Evans, and A. Silveira, Jr., Heterocycles, 1989, 28, $55-58$.

171. Organic Syntheses Using Zirconium Compounds - Recent Developments (in Japanese).

E. Negishi and T. Takahashi, J. Synth. Org. Chem., Japan, 1989, 47, 2-10.

172. Synthesis of Cyclopentanol Derivatives via Palladium-Catalyzed Cyclic AllylpalladationDehydropalladation.

E. Negishi, S. Iyer, and C. J. Rousset, Tetrahedron Lett., 1989, 30, 291-294.

173. Transition Metal-Promoted Carbon-Carbon Bond Formation Involving $\alpha$ - and $\gamma$-Heterosubstituted Carbanions.

E. Negishi, K. Akiyoshi, B. O'Connor, K. Takagi, and G. Wu, J. Am. Chem. Soc., 1989, 111, 3089-3091.

174. Novel Bicyclization of Enynes and Diynes Promoted by Zirconocene Derivatives and Conversion of Zirconabicycles into Bicyclic Enones via Carbonylation.

E. Negishi, S. E. Holmes, J. M. Tour, J. A. Miller, F. E. Cederbaum, D. R. Swanson, and T. Takahashi, J. Am. Chem. Soc., 1989, 111, 3336-3346. 
175. Palladium-Catalyzed Cascade Carbometallation of Alkynes and Alkenes as an Efficient Route to Cyclic and Polycyclic Structures.

Y. Zhang and Negishi, J. Am. Chem. Soc., 1989, 111, 3454-3456.

176. Zirconocene-Olefin Complexes: An X-Ray Structure and A Novel Preparative Method.

T. Takahashi, M. Murakami, M. Kunishige, M. Saburi, Y. Uchida, K. Kozawa, T. Uchida, D. R. Swanson, and E. Negishi, Chem. Lett., 1989, 761-764.

177. Carbon-Carbon Bond Formation via Opening of Epoxysilanes with Organometals Containing Lithium and Copper.

Y. Zhang, J. A. Miller, and E. Negishi, J. Org. Chem., 1989, 54, 2043-2044.

178. Palladium-Catalyzed Cyclization of Benzyl Halides and Related Electrophiles Containing Alkenes and Alkynes as a Novel Route to Carbocycles.

G. Wu, F. Lamaty, and E. Negishi, J. Org. Chem., 1989, 54, 2507-2508.

179. Preparation of a Hafnocene-Ethylene Complex from Bis $\left(\eta^{5}\right.$-cyclopentadienyl)-hafnacyclopentane and Its Characterization.

T. Takahashi, M. Tamura, M. Saburi, Y. Uchida, and E. Negishi, J. Chem. Soc., Chem. Commun., $1989,852-853$.

180. The Formation of the Carbon-Boron Bond from Organoboranes.

E. Negishi, "Inorganic Reactions and Methods", Vol. 10, J. J. Zuckerman and A. D. Hagen, Eds., VCH Publishers, Inc., New York, 1989, p. 91-118.

181. Metal-Organic Approach to the Stereoselective Synthesis of Exocyclic Alkenes.

E. Negishi, Advan. Metal-Org. Chem., 1989, 1, 177-207

182. Regio- and Diastereoselective Alkyl-Alkene and Alkene-Alkene Coupling Promoted by Zirconocene and Hafnocene.

D. R. Swanson, C. J. Rousset, E. Negishi, T. Takahashi, T. Seki, M. Saburi, and Y. Uchida, J. Org. Chem., 1989, 54, 3521-3523.

183. Carbonylative Cyclization via Intramolecular Trapping of Acylmetal Derivatives by Carbon 
Nucleophiles Catalyzed by Late Transition Metals.

E. Negishi, Y. Zhang, I. Shimoyama, and G. Wu, J. Am. Chem. Soc., 1989, 111, 8018-8020.

184. Zirconocene-Promoted Stereoselective Bicyclization of 1,6- and 1,7-Dienes to Produce transZirconabicyclo[3.3.0]octanes and cis-Zirconabicyclo[4.3.0.]onanes.

C. J. Rousset, D. R. Swanson, F. Lamaty, and E. Negishi, Tetrahedron Lett., 1989, 30, 5105-5108.

185. Stereoselective Synthesis of Exocyclic Alkenes via Zirconium-Promoted Alkyl-Diene Coupling. E. Negishi and S. R. Miller, J. Org. Chem., 1989, 54, 6014-6016.

186. Cyclization, Coupling, and Rearrangement Reactions of Organozirconium and Related Compounds. E. Negishi, Chimica Scripta, 1989, 29, 457-468.

187. Selective Skeletal Rearrangement by Carbon-Carbon Bond Activation. T. Takahashi, T. Fujimori, T. Seki, M. Saburi, Y. Uchida, C. J. Rousset, and E. Negishi, J. Chem. Soc., Chem. Commun., 1990, 182-183.

188. Stereoselective Cyclic Carbolithiation of Alkyne Derivatives. A Stereoselective Synthesis of Exocyclic Alkenes.

G. Wu, F. E. Cederbaum, and E. Negishi, Tetrahedron Lett., 1990, 31, 493-496.

189. Synthesis of Enol Esters via Palladium-Catalyzed Carbonylation of Aryl and Alkenyl Halides. I. Shimoyama, Y. Zhang, G. Wu, and E. Negishi, Tetrahedron Lett., 1990, 31, 2841-2844.

190. Effects of Organometals on the Palladium-Catalyzed Tandem Carbopalladation-Cross Coupling for Preparing Stereodefined Exocyclic Alkenes.

E. Negishi, Y. Noda, F. Lamaty, and E. J. Vawter, Tetrahedron Lett., 1990, 31, 4393-4396.

191. Nondissociative Mechanism for Decomposition of Dialkylzirconocenes to produce AlkeneZirconocene-Phosphine Complexes.

E. Negishi, D. R. Swanson, and T. Takahashi, J. Chem. Soc., Chem. Commun., 1990, 18, 1254-1255.

192. Clean and Convenient Procedure for Converting Primary Alkyl Iodides and $\alpha, \omega$-Diiodoalkanes into 
the Corresponding Alkyllithium Derivatives by Treatment with $t$-Butyllithium.

E. Negishi, D. R. Swanson, and C. J. Rousset, J. Org. Chem., 1990, 55, 5406-5409.

193. Palladium-Catalyzed One-Step Tri- and Tetracyclization of Acyclic Polyenynes. A Novel Route to a Steroidal Skeleton.

Y. Zhang, G. Wu, G. Agnel, and E. Negishi, J. Am. Chem. Soc., 1990, 112, 8590-8592.

194. Reaction of Dimethylzirconocene with Alkylmagnesium Halides as a Potentially General Method for Preparing Zirconocene-Alkene Complexes.

T. Takahashi, Y. Nitto, T. Seki, M. Saburi, and E. Negishi, Chem. Lett., 1990, 2259-2262.

195. Novel Zirconium-Promoted Carbon-Carbon Bond Formation via a 1,2-Migration Reaction of Alkynylzirconium Derivatives.

K. Takagi, C. J. Rousset, and E. Negishi, J. Am. Chem. Soc., 1991, 113, 1440-1442.

196. General and Convenient Procedure for the Preparation of Zirconocene Complexes of Alkenes and Conjugated Dienes.

D. R. Swanson and E. Negishi, Organometallics, 1991, 10, 825-826.

197. A Convenient Procedure for Hydrozirconation of Alkynes with $i$ - $\mathrm{BuZrCp}{ }_{2} \mathrm{Cl}$ Generated in Situ by Treatment of $\mathrm{Cp}_{2} \mathrm{ZrCl}_{2}$ with $t$-BuMgCl.

D. R. Swanson, T. Nguyen, Y. Noda, and E. Negishi, J. Org. Chem., 1991, 56, 2590-2591.

198. Remarkably "Pair" -Selective and Regioselective Carbon-Carbon Bond Forming Reaction of Zirconacylclopentane Derivatives with Grignard.

T. Takahashi, T. Seki, Y. Nitto, M. Saburi, C. J. Rousset, and E. Negishi, J. Am. Chem. Soc., 1991, 113, 6266-6268.

199. Highly Stereoselective Synthesis of Conjugated E,E- and E,Z-Dienes, E-Enynes, and E-1,2,3Butatrienes via Alkenylborane Derivatives.

E. Negishi, T. Yoshida, A. Abramovitch, G. Lew, and R. M. Williams, Tetrahedron, 1991, 47, 343-356.

200. Zirconium-promoted Bicyclization of Enynes. 
E. Negishi, "Comprehensive Organic Synthesis", Vol. 5, B. M. Trost, Ed., Pergamon, 1991, 1163-1184.

201. Strictly Regio-Controlled Method for $\alpha$-Alkenylation of Cyclic Ketones via Palladium-Catalyzed Cross Coupling.

E. Negishi, Z. Owczarczyk, and D. R. Swanson, Tetrahedron Lett., 1991, 32, 4453-4456.

202. Highly Stereo- and Regiocontrolled Cyclopentannulation via Allylphosphonate Conjugate Addition and Hydroboration-Oxidation-Elimination. Synthesis of Pentalenic Acid with Virtually Complete Stereo- and Regiocontrol.

G. Agnel and E. Negishi, J. Am. Chem. Soc., 1991, 113, 7424-7426.

203. Zirconium-Catalyzed, Highly Regioselective Hydrosilation Reaction of Alkenes and X-Ray Structures of Silyl(hydrido)zirconocene Derivatives.

T. Takahashi, M. Hasegawa, N. Suzuki, M. Saburi, C. J. Rousset, P. E. Fanwick, and E. Negishi, J. Am. Chem. Soc., 1991, 113, 8564-8566.

204. Catalytic Hydrogenation of Alkenes Using Zirconocene-Alkene Complexes.

T. Takahashi, N. Suzuki, M. Kageyama, Y. Nitto, M. Saburi, and E. Negishi, Chem. Lett., 1991, 1579-1582.

205. Highly Selective Synthesis of Vitamin A and its Derivatives. Critical Comparison of Some Known Palladium-Catalyzed Alkenyl-Alkenyl Coupling Reactions.

E. Negishi and Z. Owczarczyk, Tetrahedron Lett., 1991, 32, 6683-6686.

206. Palladium-Catalyzed Carbonylative Cyclization of o-Allylbenzyl Halides to Produce BenzoAnnulated Enol Lactones and/or Bicyclo[3.3.0]hept-3-en-6-ones. An Efficient Route to U-68,215. G. Wu, I. Shimoyama, and E. Negishi, J. Org. Chem., 1991, 56, 6506-6507.

207. Carbon-Carbon Bond Formation by the Reaction of Organolithiums with $\alpha$-Lithiated Cyclic Enol Ethers. Stereoselective Synthesis of $\beta$ - and $\gamma$-Hydroxy Di- and Tri-Substituted Alkenes.

T. Nguyen and E. Negishi, Tetrahedron Lett., 1991, 32, 5903-5906.

208. Novel Head-to-Tail Alkyl-Alkene or Alkene-Alkene Coupling via Zirconium-Catalyzed Reaction of 
Alkylmagnesium Derivatives with Monosubstituted Alkenes.

C. J. Rousset, E. Negishi, N. Suzuki, and T. Takahashi, Tetrahedron Lett., 1992, 33, 1965-1968.

209. Zipper-Mode Cascade Carbometallation for Construction of Polycyclic Structures.

E. Negishi, Pure Appl. Chem., 1992, 74, 323-334.

210. Zirconocene-Alkene Complexes: Their Formation, Structure, and Reactions.

E. Negishi and T. Takahashi, Rev. Heteroatom Chem., 1992, 6, 177-201.

211. Diastereoselective Zirconocene-Promoted Bicyclization-Carbonylation of Allylically MethylSubstituted Enynes. Synthesis of (+)-Iridomyrmecin.

G. Agnel, Z. Owczarczyk, and E. Negishi, Tetrahedron Lett., 1992, 33, 1543-1546.

212. Cyclization Reactions of $\omega$-Tosyloxy-1-alkynyl- and $\omega$-Tosyloxy-1-alkenylborates and Their $\omega$-Halo Analogues.

E. Negishi, T. Nguyen, L. D. Boardman, H. Sawada, and J. A. Morrison, Heteroatom Chem., 1992, 3, 293-302.

213. Cyclic Cascade Carbopalladation Reactions as a Route to Benzene and Fulvene Derivatives.

E. Negishi, L. S. Harring, Z. Owczarczyk, M. M. Mohamud, and M. Ay, Tetrahedron Lett., 1992, 33, 3253-3256.

214. Factors Affecting the Unusual Reactivity Order in the $\beta$-Hydrogen Abstraction of Dialkylzirconocenes.

E. Negishi, T. Nguyen, J. P. Maye, D. Choueiri, N. Suzuki, and T. Takahashi, Chem. Lett., 1992, 2367-2370.

215. Apparent Endo-Mode Cyclic Carbopalladation with Inversion of Alkene Configuration via Exo-Mode Cyclization-Cyclopropanation-Rearrangement.

Z. Owczarczyk, F. Lamaty, E. J. Vawter, and E. Negishi, J. Am. Chem. Soc., 1992, 114, 10091-10092.

216. Facile Cleavage of the $\mathrm{C}-\mathrm{C}^{\prime}$ Bond of Zirconacyclopentenes. Convenient Method for Selectively Coupling Alkynes with Alkynes, Nitriles, and Aldehydes. 
T. Takahashi, M. Kageyama, V. Denisov, R. Hara, and E. Negishi, Tetrahedron Lett., 1993, 34, 687-690.

217. Highly Stereoselective and General Synthesis of (Z)-3-Methyl-2-alken-1-ols via PalladiumCatalyzed Cross Coupling of (Z)-3-Iodo-2-buten-1-ol with Organozincs and Other Organometals.

E. Negishi, M. Ay, Y. V. Gulevich, and Y. Noda, etrahedron Lett., 1993, 34, 1437-1440.

218. Selective Synthesis of Benzene Derivatives via Palladium-Catalyzed Cascade Carbometallation of Alkynes.

E. Negishi, M. Ay, and T. Sugihara, Tetrahedron, 1993, 49, 5471-5482.

219. Conversion of Non-conjugated Dienes into Conjugated Diene-Zirconocenes via Multipositional Regioisomerization.

J. P. Maye and E. Negishi, Tetrahedron Lett., 1993, 34, 3359-3362.

220. Zirconium Catalyzed C-C Bond Formation Reaction of Conjugated Diynes with EtMgBr.

T. Takahashi, K. Aoyagi, V. Denisov, N. Suzuki, D. Choueiry, and E. Negishi, Tetrahedron Lett., 1993, 34, 8301-8304.

221. Convenient Synthesis of Diene-Zirconocenes and Regioselective Partial Reduction of the More Highly Substituted Double Bonds of Conjugated Dienes via Complexation with Zirconocenes and Protonolysis.

J. P. Maye and E. Negishi, J. Chem. Soc. Chem. Commun., 1993, 1830-1831.

222. Palladium-Catalyzed Carbonylative Cyclization via Trapping of Acylpalladium Derivatives with Internal Enolates. Its Scope and Factors Affecting the C-to-O Ratio.

E. Negishi, C. Copéret, T. Sugihara, I. Shimoyama, Y. Zhang, G. Wu, and J. M. Tour, Tetrahedron, 1994, 50, 425-436.

223. Reaction of 3-Zircona-1-cyclopentenes and Zirconacyclopentanes with Aldehydes. A Selective and Convenient Synthesis of 4-Penten-1-ols, (Z)-5-Iodo-4-penten-1-ols, and Related Alkanols.

C. Copéret, E. Negishi, Z. Xi, and T. Takahashi, Tetrahedron Lett., 1994, 35, 695-698.

224. Isolation and Characterization of the Ethylene-Bridged Zirconocene Complex 
$\left(\mathrm{Cp}_{2} \mathrm{ZrMe}\right)_{2}\left(\mathrm{CH}_{2} \mathrm{CH}_{2}\right)$.

T. Takahashi, K. Kasai, N. Suzuki, K. Nakajima, and E. Negishi, Organometallics, 1994, 13, 3413-3414.

225. Patterns of Stoichiometric and Catalytic Reactions of Organozirconium and Related Complexes of Synthetic Interest.

E. Negishi and T. Takahashi, Acc. Chem. Res., 1994, 27, 124-130.

226. Deferred Carbonylative Esterification in the Pd-Catalyzed Cyclic Carbometallation-Carbonylation Cascade.

T. Sugihara, C. Copéret, Z. Owczarczyk, L. S. Harring, and E. Negishi, J. Am. Chem. Soc., 1994, 116, 7923-7924.

227. Facile Formation of Seven- and Eight-Membered Cycloalkenes via Catalytic and Cyclic Carbopalladation of Allenes.

S. Ma and E. Negishi, J. Org. Chem., 1994, 59, 4730-4732.

228. Titanium-Catalyzed Cascade Carboalumination of Dienes and Trienes.

E. Negishi, M. J. Jensen, D. Y. Kondakov, and S. Wang, J. Am. Chem. Soc., 1994, 116, 8404-8405.

229. Nonconcerted Paths for Reactions of Alkene-Zirconocene Complexes.

E. Negishi, D. Choueiry, T. B. Nguyen, D. R. Swanson, N. Suzuki, and T. Takahashi, J. Am. Chem. Soc., 1994, 116, 9751-9752.

230. Novel Structures and Reaction Patterns in Organozirconium and Related Chemistry.

E. Negishi, Seminars in Organic Synthesis: XIX Summer School "A. Corbella", Società Chimica. Italiana, 1994, p. 7-24.

231. Termination of Carbopalladation of Alkynes via Carbonylative Amidation Producing Lactams.

C. Copéret, T. Sugihara, and E. Negishi, Tetrahedron Lett., 1995, 36, 1771-1774.

232. Stoichiometric Reactions of Nonconjugated Dienes with Zirconocene Derivatives. Further Delineation of the Scope of Bicyclization and Observation of a Novel Multipositional Alkene Regioisomerization. 
E. Negishi, J. P. Maye, and D. Choueiry, Tetrahedron, 1995, 51, 4447-4462.

233. Acylpalladation of Internal Alkynes and Palladium-Catalyzed Carbonylation of (Z)- $\beta$-Iodoenones Related Derivatives Producing $\gamma$-Lactones and $\gamma$-Lactams.

C. Copéret, T. Sugihara, G. Wu, I. Shimoyama, and E. Negishi, J. Am. Chem. Soc., 1995, 117, 3422-3431.

234. Palladium-Catalyzed Cyclization of $\omega$-Haloallenes. A New General Route to Common, Medium, and Large Ring Compounds via Cyclic Carbopalladation.

S. Ma and E. Negishi, J. Am. Chem. Soc., 1995, 117, 6345-6357

235. Zirconium-Catalyzed Enantioselective Methylalumination of Monosubstituted Alkenes.

D. Kondakov and E. Negishi, J. Am. Chem. Soc., 1995, 117, 10771-10772.

236. 1-Chloro-2-iodoethylene.

E. Negishi and C. Copéret, "Encyclopedia of Reagents for Organic Synthesis", L. A. Paquette, ed. Wiley, New York, 1995, Vol. 2, 1142-1143.

237. $n$-Butyllithium-Dichlorobis $\left(\eta^{5}\right.$-cyclopentadienyl)zirconium. Di(n-butyl)zirconocene.

E. Negishi, "Encyclopedia of Reagents for Organic Synthesis", L. A. Paquette, ed. Wiley, New York, 1995, Vol. 3, 1593-1596.

238. Trimethylaluminum-Dichlorobis $\left(\eta^{5}\right.$-cyclopentadienyl)titanium.

E. Negishi and D. Choueiry, "Encyclopedia of Reagents for Organic Synthesis", L. A. Paquette, ed. Wiley, New York, 1995, Vol. 7, 5190-5192.

239. Trimethylaluminum-Dichlorobis $\left(\eta^{5}\right.$-cyclopentadienyl)zirconium.

E. Negishi and D. Choueiry, "Encyclopedia of Reagents for Organic Synthesis", L. A. Paquette, ed. Wiley, New York, 1995, Vol. 7, 5192-5195.

240. The Synthesis of Vinyl- and Arylmetals.

E. Negishi and D. Choueiry, "Organic Functional Group Transformations," A. R. Katritzky, O. Meth-Cohn, and C. W. Rees, eds., Pergamon Press, Oxford, 1995, Vol. 2, 951-995. 
241. Cyclic Carbopalladation. A Versatile Synthetic Methodology for the Construction of Cyclic Organic Compounds

E. Negishi, C. Copéret, S. Y. Liou, F. Liu, and S. Ma, Chem. Rev., 1996, 96, 365-393.

242. Zirconium-Catalyzed Enantioselective Alkylalumination of Monosubstituted Alkenes Proceeding via Noncyclic Mechanism.

D. Y. Kondakov and E. Negishi, J. Am. Chem. Soc., 1996, 118, 1577-1578.

243. Palladium-Catalyzed Carbonylative Cyclization of 1-Iodo-2-alkenylbenzenes E. Negishi, C. Copéret, S. Ma, T. Mita, T. Sugihara, and J. M. Tour, J. Am. Chem. Soc., 1996, 118, 5904-5918.

244. Palladium-Catalyzed Cyclization of 1-Iodo-Substituted 1,4-, 1,5-, and 1,6-Dienes as Well as of 5-Iodo-1,5-dienes in the Presence of Carbon Monoxide.

E. Negishi, S. Ma, J. Amanfu, C. Copéret, J. A. Miller, and J. M. Tour, J. Am. Chem. Soc., 1996, 118, 5919-5931.

245. Titanium-Catalyzed Cascade Carboalumination of 2-Alkyl-Substituted Dienes and Trienes D. Y. Kondakov, S. Wang, and E. Negishi, Tetrahedron Lett., 1996, 37, 3803-3806.

246. Facile and Reversible Formation of Monocyclopentadienylzirconium Derivatives by the Reaction of $\mathrm{Cp}_{2} \mathrm{ZrCl}_{2}$ with Alkyllithiums and Their Reactions with Electrophiles and Olefins.

D. Y. Kondakov and E. Negishi, J. Chem. Soc., Chem. Commun., 1996, 963-964.

247. Palladium-Catalyzed Cascading Carbonylative Cyclization of Iodo-Dienes and -Trienes. C. Copéret, S. Ma, and E. Negishi, Angew. Chem., Int. Ed. Engl., 1996, 2125-2126.

248. A Selective Procedure of $\alpha$-Alkenylation of Enones Involving Pd-Catalyzed Alkenyl-Alkenyl Coupling and Its Application of a Convergent and Efficient Synthesis of Nakienone B.

M. Pour and E. Negishi, Tetrahedron Lett., 1996, 37, 4679-4682.

249. Cyclic Carbopalladation of Alkynes Terminated by Carbonylative Amidation.

C. Copéret, S. Ma, T. Sugihara, and E. Negishi, Tetrahedron, 1996, 52, 11529-11544. 
250. Reaction of Alkynes with Organometallic Reagents.

E. Negishi and D. Choueiry, "Preparation of Alkynes: A Practical Approach," J. M. J. Williams, Ed., Oxford University Press, Oxford, 137-156.

251. Multiple Mechanistic Pathways for Zirconium-Catalyzed Carboalumination of Alkynes.

E. Negishi, D. Y. Kondakov, D. Choueiry, K. Kasai, and T. Takahashi, J. Am. Chem. Soc., 1996, 118, $9577-9588$.

252. An Odyssey from Stoichiometric Carbotitanation of Alkynes to Zirconium-Catalyzed Enantioselective Carboalumination of Alkenes.

E. Negishi and D. Y. Kondakov, Chem. Soc. Rev., 1996, 26, 417-426.

253. Convenient and General Synthesis of 1-Monoorganyl- and 1,2,-Diorganylcyclobutenes via Cyclialkylation.

E. Negishi, F. Liu, D. Choueiry, M. M. Mohamud, A. Silveira, Jr., and M. Reeves, J. Org. Chem., 1996, 61, 8325-8328.

254. Efficient and Diastereoselective Synthesis of (+)-Goniobutenolide A via Palladium-Catalyzed Ene-Yne Cross Coupling-Lactonization Cascade.

M. Kotora and E. Negishi, Tetrahedron Lett., 1996, 37, 9041-9042.

255. Highly Efficient and Selective Procedures for the Synthesis of $\gamma$-Alkylidenebutenolides and Its Application to the Synthesis of Rubrolides A, C, D, and E.

M. Kotora and E. Negishi, Synthesis, 1997, 121-128.

256. An Efficient and Selective Synthesis of Nakienone A Involving a Novel Protocol of $\alpha$-Alkenylation of Ketones via Palladium-Catalyzed Alkenyl-Alkenyl Coupling.

M. Pour and E. Negishi, Tetrahedron Lett., 1997, 38, 525-528

257. On the Regiochemistry of Cyclialkylation of Regiodefined 4-Halo-1-alkenylmetals Producing Cyclobutenes.

F. Liu and E. Negishi, Tetrahedron Lett., 1997, 38, 1149-1152.

258. Anti-Carbometallation of Homopropargyl Alcohols and Their Higher Homologues via Non- 
Chelation-Controlled Syn-Carbometallation and Chelation-Controlled Isomerization.

S. Ma and E. Negishi, J. Org. Chem., 1997, 62, 784-785.

259. Carbometallation Reactions of Diphenylacetylene and Other Alkynes with Methylalanes and Titanocene Derivatives.

E. Negishi, D. Y. Kondakov, and D. E. Van Horn, Organometallics, 1997, 16, 951-957.

260. Regio- and Stereoselective Synthesis of $\gamma$-Alkylidenebutenolides and Related Compounds.

E. Negishi and M. Kotora, Tetrahedron, 1997, 53, 6707-6738.

261. Synthesis of Hydrazulenes via Zr-Promoted Bicyclization of Enynes and Transition MetalCatalyzed or Radical Cyclization of Alkenyl Iodides. Efficient Synthesis of $( \pm)$-7-epi- $\beta$-Bulnesene.

E. Negishi, S. Ma, T. Sugihara, and Y. Noda, J. Org. Chem., 1997, 62, 1922-1923.

262. Pd- or Ni-Catalyzed Cross Coupling with Organometals Containing Zn, Mg, Al, and Zr.

E. Negishi and F. Liu, Chapter 1 in Cross Coupling Reactions, P. J. Stang and F. Diederich, Eds., VCH, Weinheim, 1998, p. 1-47.

263. Anti-Hydroalumination of Homo- and Bishomopropargyl Alcohols.

S. Ma, F. Liu, and E. Negishi, Tetrahedron Lett., 1997, 38, 3829-3832.

264. Convenient Preparative Method of $\alpha, \beta$-Disubstituted Cyclopentenone by Zirconocene-Promoted Intermolecular Coupling of an Alkyne, $\mathrm{EtMgBr}$ (or Ethylene) and $\mathrm{CO}$.

T. Takahashi, Z. Xi, Y. Nishihara, S. Huo, K. Kasai, K. Aoyagi, V. Denisov, and E. Negishi, Tetrahedron, 1997, 53, 9123-9134.

265. Direct Synthesis of Heteroarylethynes via Palladium-Catalyzed Coupling of Heteroaryl Halides with Ethynylzinc Halides. Its Application to an Efficient Synthesis of a Thiophenelactone from Chamaemelum Nobile L.

E. Negishi, C. Xu, Z. Tan, and M. Kotora, Heterocycles, 1997, 46, 209-214.

266. Efficient and Stereoselective Synthesis of Freelingyne via Pd-Catalyzed Cross Coupling and Lactonization.

F. Liu and E. Negishi, J. Org. Chem., 1997, 62, 8591-8594. 
267. Convenient and Direct Synthesis of Terminal Alkynes via Pd-Catalyzed Cross Coupling. Critical Comparison of Countercations.

E. Negishi, M. Kotora, and C. Xu, J. Org. Chem., 1997, 62, 8957-8960.

268. Enantiomerically Pure Zirconium and Hafnium Complexes Containing a Chiral Cyclopentadiene Derivative Prepared from (-)- $\beta$-Pinene.

C. J. Rousset, S. Iyer, and E. Negishi, Tetrahedron: Asymmetry, 1997, 8, 3921-3926.

269. Catalytic Generation and Trapping of Acylmetals Containing Ni and $\mathrm{Cu}$ with Enolates.

E. Negishi, H. Makabe, I. Shimoyama, G. Wu, and Y. Zhang, Tetrahedron, 1998, 54, 1095-1106.

270. Alkene and Alkyne Complexes at Zirconocene. Their Preparation, Structure and Novel Transformations.

E. Negishi and T. Takahashi, Bull. Chem. Soc. Jpn., 1998, 71, 755-769.

271. Carbozincation of Enynes Catalyzed by Titanium(IV) Alkoxides and Alkylmagnesium Derivatives. J.-L. Montchamp and E. Negishi, J. Am. Chem. Soc., 1998, 120, 5345-5346.

272. Zirconium-Catalyzed and Zirconium-Promoted Cyclization Reactions of Nonconjugated Dienes with Alkylmagnesium Halides to Give Cycloalkylmethylmagnesium Derivatives.

E. Negishi, C. J. Rousset, D. Choueiry, J. P. Maye, N. Suzuki, and T. Takahashi, Inorg. Chim. Acta, 1998, 280/1-2, 8-20.

273. Zirconium-Catalyzed Carboalumination of Alkynes and Enynes as a Route to Aluminacycles and Their Conversion to Cyclic Organic Compounds.

E. Negishi, J.-L. Montchamp, L. Anastasia, A. Elizarov, and D. Choueiry, Tetrahedron Lett., 1998, 39, 2503-2506.

274. Strictly Regio- and Stereo-Controlled $\alpha$-Alkenylation of Bicyclic Enones and Their Derivatives via Palladium-Catalyzed Cross Coupling and Its Application to a Formal Synthesis of ( \pm )-Carbacyclin.

E. Negishi, M. Pour, F. E. Cederbaum, and M. Kotora, Tetrahedron, 1998, 54, 7057-7074.

275. Zirconocenes.

E. Negishi and J. L. Montchamp, Chapter 5 in Metallocenes, A. Togni and R. L. Halterman, Eds., 
VCH, Weinheim, 1998, 241-319.

276. Selective Intermolecular Coupling of Alkynes with Nitriles and Ketones via $\beta, \beta^{\prime}$ Carbon-Carbon Bond Cleavage of Zirconacyclopentenes.

T. Takahashi, C. Xi, Z. Xi, M. Kageyama, R. Fischer, K. Nakajima, and E. Negishi, J. Org. Chem., 1998, 63, 6802-6806.

277. Palladium- and Nickel-Catalyzed Reactions of Organozinc Compounds.

E. Negishi, Chapter 11 in Organozinc Reagents: A Practical Approach, P. Knochel and P. Jones, Ed., Oxford University Press, Oxford, 1999, 213-243.

278. A Highly Efficient and Selective Synthesis of Lissoclinolide Featuring Hydrogen Transfer Hydrozirconation, trans-Selective Pd-Catalyzed Cross Coupling of Alkenylzirconiums with 1,1-Dibromoalkenes and Ag-Catalyzed Lactonization Providing ( $Z$ )- $\gamma$-Alkylidenebutenolides.

C. Xu and E. Negishi, Tetrahedron Lett., 1999, 40, 431-434.

279. Intermolecular Trapping of Acylpalladium and Related Acylmetal Derivatives with Active C-H Compounds.

E. Negishi, S.-Y. Liou, C. Xu, I. Shimoyama, and H. Makabe, J. Mol. Cat., 1999, 143, 279-286.

280. Principle of Activation of Electrophiles by Electrophiles through Dimeric Association - Two is Better than One.

E. Negishi, Chem. Eur. J., 1999, 5, 411-420.

281. Palladium-Catalyzed Highly Diastereoselective Cyclic Carbopalladation-Carbonylative Esterification Tandem Reaction of Iododienes and Iodoarylalkenes.

C. Coperét and E. Negishi, Org. Lett., 1999, 1, 165-167.

282. Hydrogen Transfer Hydrozirconation of Alkenes with $i-\mathrm{BuZrCp} \mathrm{p}_{2} \mathrm{Cl}$ Catalyzed by Lewis-Acidic Metal Compounds Containing Al, Zn, Si, Ag, Ni, and Pd.

H. Makabe and E. Negishi, Eur. J. Org. Chem., 1999, 969-971.

283. Synthesis of $\alpha$-Iodo- $\alpha, \beta$-unsaturated Ketones by the Reaction of $\alpha$-Silyl- $\alpha, \beta$-unsaturated Ketones with $\mathrm{ICl}$ or $\mathrm{ICl}-\mathrm{AlCl}_{3}$. 
A. Alimardanov and E. Negishi, Tetrahedron Lett., 1999, 40, 3839-3842.

284. Highly Chemo-, Regio-, and Stereoselective Carbon-Carbon Bond Formation via Migratory Insertion Reaction of Zirconacyclopentene Derivatives and Alkynylmetals Containing Li and Mg. Novel Synthesis of 1,5-Dienes and 1,5-Enynes.

Y. Dumond and E. Negishi, J. Am. Chem. Soc., 1999, 121, 11223-11224.

285. Novel and Selective $\alpha$-Substitution of Ketones and Other Carbonyl Compounds Based on Pd-Catalyzed Cross Coupling of $\alpha, \beta$-Unsaturated Carbonyl Derivatives Containing $\alpha$-Halogen or $\alpha$-Metal Groups.

E. Negishi, J. Organomet. Chem., 1999, 576, 179-194.

286. Novel and Selective $\alpha$-Substitution of Ketones and Other Carbonyl Compounds Based on Pd-Catalyzed Cross Coupling of $\alpha, \beta$-Unsaturated Carbonyl Derivatives Containing $\alpha$-Halogen or $\alpha$-Metal Groups.

E. Negishi, In Perspective in Organopalladium Chemistry for the 21 Century,” J. Tsuji, Ed., Elsevier, 1999, 179-194.

287. An Efficient and Stereoselective Synthesis of Xerulin via Pd-Catalyzed Cross Coupling and Lactonization Featuring (E)-Iodobromoethylene as a Novel Two-Carbon Synthon.

E. Negishi, A. Alimardanov, and C. Xu, Org. Lett., 2000, 2, 65-67.

288. A General Method for the Synthesis of $E$ and/or $Z$ Oligoisoprenoids Based on Pd-Catalyzed Homoallyl-Alkenyl and Homopropargyl-Alkenyl Cross Coupling and Zr-Catalyzed Carboalumination.

E. Negishi, S. Y. Liou, C. Xu, and S. Huo, Polyhedron, 2000, 19, 591-592.

289. Development of a Method for the Synthesis of $\alpha$-Substituted $\alpha, \beta$-Unsaturated Lactones Based on Stille-Type Pd-Catalyzed Carbonylation of (Z)- $\omega$-Iodoalkenols. An Efficient and Selective Synthesis of (+)-Hamabiwalactone B.

B. Liao and E. Negishi, Heterocycles, 2000, 52, 1241-1249.

290. Asymmetric Carbometallations.

E. Negishi, Chapter 4 in Catalytic Asymmetric Synthesis II, I. Ojima, Ed., J. Wiley-VCH, New York, 
2000, 165-189.

291. Ethylzincation of Monosubstituted Alkenes Catalyzed by EtMgBr- $\mathrm{Cl}_{2} \mathrm{ZrCp}_{2}$ and Palladium-Catalyzed Cross Coupling of the Resultant Diisoalkylzinc Derivatives.

S. Gagneur, J. L. Montchamp, and E. Negishi, Organometallics, 2000, 19, 2417-2419.

292. A Strictly "Pair"-Selective Synthesis of Conjugated Diynes via Pd-Catalyzed Cross Coupling of 1,3-Diynylzincs: A Superior Alternative to the Cadiot-Chodkiewicz Reaction.

E. Negishi, M. Hata, and C. Xu, Org. Lett., 2000, 2, 3687-3689.

293. Strictly Regiocontrolled $\alpha$-Monosubstitution of Cyclic Carbonyl Compounds with Alkynyl and Alkyl Groups via Pd-Catalyzed Coupling of Cyclic $\alpha$-Iodoenones with Organozincs.

E. Negishi, Z. Tan, S. Y. Liou, and B. Liao, Tetrahedron, 2000, 56, 10197-10207.

294. A Novel Hydrogen Transfer Hydroalumination of Alkenes with Triisobutylaluminum Catalyzed by $\mathrm{Pd}$ and Other Late Transition Metal Complexes.

S. Gagneur, H. Makabe, and E. Negishi, Tetrahedron Lett., 2001, 42, 785-787.

295. Some Newer Aspects of Organozirconium Chemistry of Relevance to Organic Synthesis. Zr-Catalyzed Enantioselective Carbometallation.

E. Negishi, Pure Appl. Chem., 2001, 73, 239-242.

296. A Novel, Selective, and Efficient Route to Carotenoids and Related Natural Products via Zr-Catalyzed Carboalumination and Pd- and Zn-Catalyzed Cross Coupling.

F. Zeng and E. Negishi, Org. Lett., 2001, 3, 719-722.

297. Stereoselective Synthesis of Exocyclic Alkenes via Cu-Catalyzed Allylmagnesiation, Pd-Catalyzed Alkylation, and Ru-Catalyzed Ring Closing Olefin Metathesis: Highly Stereoselective Synthesis of $(Z)$ - and $(E)-\gamma$-Bisabolenes.

Y. Dumond, L. Anastasia, and E. Negishi, Eur. J. Org. Chem., 2001, 3039-3043.

298. Highly Satisfactory Procedures for the Pd-Catalyzed Cross Coupling of Aryl Electrophiles with in Situ Generated Alkynylzinc Derivatives.

L. Anastasia and E. Negishi, Org. Lett., 2001, 3, 3111-3113. 
299. A Convenient and Asymmetric Protocol for the Synthesis of Natural Products Containing Chiral Alkyl Chains via Zr-Catalyzed Asymmetric Carboalumination of Alkenes. Syntheses of Phytol and Vitamins E and K.

S. Huo and E. Negishi, Org. Lett., 2001, 3, 3253-3256.

300. Organozirconium Chemistry in Organic Synthesis.

E. Negishi, Chapter 8 in Organometallics in Synthesis: A Manual, $2^{\text {nd }}$ Ed., M. Schlosser, Ed., Wiley, New York, 2002, 926 - 1002.

301. Zirconium-Catalyzed Enantioselective Carboalumination of "Unactivated" Alkenes as a New Synthetic Tool for Asymmetric Carbon-Carbon Bond Formation.

E. Negishi and S. Huo, Pure Appl. Chem., 2002, 74, 151-157.

302. A Genealogy of Pd-Catalyzed Cross Coupling.

E. Negishi, J. Organomet. Chem., 2002, 653, 34-40.

303. Synthesis and Reactivity of Zirconocene Derivatives.

E. Negishi and S. Huo, Chapter 1 in Titanium and Zirconium in Organic Synthesis, I. Marek, Ed., Wiley-VCH, Weinheim, 2002, 1-49.

304. (-)-Dichlorobis[(1,2,3,3a,7a- $)-1-[(1 S, 2 S, 5 R)-5$-methyl-2-(1-methylethyl)]cyclohexyl-1H-inden-1yl]zirconium and Its $(+)-(1 R, 2 R, 5 S)$-Isomer.

E. Negishi and S. Huo, "Encyclopedia of Reagents for Organic Synthesis", L. A. Paquette, Ed., Wiley, New York, 2002.

305. A New Protocol for the Enantioselective Synthesis of Methyl-Substituted Chiral Alkanols and Their Derivatives via Hydroalumination-Zirconium Catalyzed Alkylalumination Tandem Process.

S. Huo, J. Shi, and E. Negishi, Angew. Chem. Int. Ed., 2002, 41, 2141-2143.

306. A Novel, Highly Selective, and General Methodology for the Synthesis of 1,5-Diene-Containing Oligoisoprenoids of All Possible Geometrical Combinations Exemplified by an Iterative and Convergent Synthesis of Coenzyme $\mathrm{Q}_{10}$.

E. Negishi, S. Y. Liou, C. Xu, and S. Huo, Org. Lett., 2002, 4, 261-264. 
307. (E)-1-Bromo-2-iodoethylene.

E. Negishi and F. Zeng, In Encyclopedia of Reagents for Organic Synthesis, L. A. Paquette, Ed., John Wiley \& Sons, Inc., New York, 2002.

308. A Highly Efficient, Selective, and General Method for the Synthesis of Conjugated (all-E)Oligoenes of the $(\mathrm{CH}=\mathrm{CH})_{\mathrm{n}}$ Type via Iterative Hydrozirconation-Palladium-Catalyzed Cross-Coupling.

F. Zeng and E. Negishi, Org. Lett., 2002, 4, 703-706.

309. Catalytic and Selective Conversion of (Z)-2-En-4-ynoic Acids to either $2 H$-Pyran-2-ones in the Presence of $\mathrm{ZnBr}_{2}$ or $(\mathrm{Z})$-5-Alkylidenefuran-2(5H)-ones in the Presence of $\mathrm{Ag}_{2} \mathrm{CO}_{3}$.

L. Anastasia, C. Xu, and E. Negishi, Tetrahedron Lett., 2002, 43, 5673-5676.

310. Handbook of Organopalladium Chemistry for Organic Synthesis, 2 Vols.

E. Negishi, Ed., Wiley-Interscience, New York, 2002, 3279 pp.

311. Fundamental Properties of Palladium and Patterns of the Reactions of Palladium and Its Complexes. E. Negishi, In The Handbook of Organopalladium Chemistry for Organic Synthesis, E. Negishi, Ed., J. Wiley \& Sons, New York, 2002, Sect. I.2, 17-35.

312. General Discussion of the Methods of Synthesis and In-Situ Generation of Organopalladium Compounds.

E. Negishi, In The Handbook of Organopalladium Chemistry for Organic Synthesis, E. Negishi, Ed., J. Wiley \& Sons, New York, 2002, Sect. II.3.1, 127-145.

313. Palladium-Catalyzed Aryl-Aryl Coupling.

L. Anastasia and E. Negishi, In The Handbook of Organopalladium Chemistry for Organic Synthesis, E. Negishi, Ed., J. Wiley \& Sons, New York, 2002, Sect. III.2.5, 311-334.

314. Palladium-Catalyzed Alkenyl-Aryl, Aryl-Alkenyl, and Alkenyl-Alkenyl Coupling Reactions. S. Huo and E. Negishi, In The Handbook of Organopalladium Chemistry for Organic Synthesis, E. Negishi, Ed., J. Wiley \& Sons, New York, 2002, Sect. III.2.6, 335-408.

315. Palladium-Catalyzed Alkynylation with Alkynylmetals or Alkynyl Electrophiles. 
E. Negishi and C. Xu, In The Handbook of Organopalladium Chemistry for Organic Synthesis, E. Negishi, Ed., J. Wiley \& Sons, New York, 2002, Sect. III.2.8.2, 531-549.

316. Palladium-Catalyzed Cross-Coupling between Allyl, Benzyl, or Propargyl Groups andUnsaturated Groups.

E. Negishi and F. Liu, In The Handbook of Organopalladium Chemistry for Organic Synthesis, E. Negishi, Ed., J. Wiley \& Sons, New York, 2002, Sect. III.2.9, 551-589.

317. Palladium-Catalyzed Cross-Coupling between Allyl-, Benzyl-, or Propargylmetals and Allyl, Benzyl, or Propargyl Electrophiles.

E. Negishi and B. Liao, In The Handbook of Organopalladium Chemistry for Organic Synthesis, E. Negishi, Ed., J. Wiley \& Sons, New York, 2002, Sect. III.2.10, 591-596.

318. Palladium-Catalyzed Cross-Coupling Involving Saturated Alkylmetals.

E. Negishi and S. Gagneur, In The Handbook of Organopalladium Chemistry for Organic Synthesis, E. Negishi, Ed., J. Wiley \& Sons, New York, 2002, Sect. III.2.11.1, 597-618.

319. Palladium-Catalyzed Cross-Coupling between Homoallyl-, Homopropargyl-, or Homobenzylmetals and Alkenyl or Aryl Electrophiles.

E. Negishi and F. Zeng, In The Handbook of Organopalladium Chemistry for Organic Synthesis, E. Negishi, Ed., J. Wiley \& Sons, New York, 2002, Sect. III.2.11.2, 619-633.

320. Palladium-Catalyzed a-Substitution Reactions of Enolates and Related Derivatives Other than the Tsuji-Trost Allylation Reaction.

E. Negishi, In The Handbook of Organopalladium Chemistry for Organic Synthesis, E. Negishi, Ed., J. Wiley \& Sons, New York, 2002, Sect. III.2.14.1, 693-719.

321. Palladium-Catalyzed Cross-Coupling Involving $\beta$-Hetero-Substituted Compounds Other than Enolates.

E. Negishi and A. Alimardanov, In The Handbook of Organopalladium Chemistry for Organic Synthesis, E. Negishi, Ed., J. Wiley \& Sons, New York, 2002, Sect. III.2.14.2, 721-766.

322. Palladium-Catalyzed Conjugate Substitution.

E. Negishi and Y. Dumond, In The Handbook of Organopalladium Chemistry for Organic Synthesis, 
E. Negishi, Ed., J. Wiley \& Sons, New York, 2002, Sect. III.2.15, 767-789.

323. Synthesis of Natural Products via Palladium-Catalyzed Cross-Coupling.

Z. Tan and E. Negishi, In The Handbook of Organopalladium Chemistry for Organic Synthesis, E. Negishi, Ed., J. Wiley \& Sons, New York, 2002, Sect. III.2.18, 863-942.

324. Palladium-Catalyzed Tandem and Cascade Carbopalladation of Alkynes and 1,1-Disubstituted Alkenes Terminated by Carbonylative Reactions.

E. Negishi and C. Copéret, In The Handbook of Organopalladium Chemistry for Organic Synthesis, E. Negishi, Ed., J. Wiley \& Sons, New York, 2002, Sect. IV.3.3, 1431-1448.

325. Palladium-Catalyzed Allylation and Related Substitution Reactions of Enolates and Related Derivatives of "Ordinary" Ketones, and Aldehydes, and Other Carbonyl Compounds.

E. Negishi and S. Y. Liou, In The Handbook of Organopalladium Chemistry for Organic Synthesis, E. Negishi, Ed., J. Wiley \& Sons, New York, 2002, Sect. V.2.1.4, 1769-1793.

326. Synthesis of Natural Products via Nucleophilic Attack on $\pi$-Ligands of Palladium-Alkene, Palladium-Alkyne, and Related $\pi$-Complexes.

C. Xu and E. Negishi, In The Handbook of Organopalladium Chemistry for Organic Synthesis, E. Negishi, Ed., J. Wiley \& Sons, New York, 2002, Sect. V.3.6, 2289-2305.

327. Reactions of Acylpalladium Derivatives with Enolates and Related Amphiphilic Reagents.

E. Negishi and H. Makabe, In The Handbook of Organopalladium Chemistry for Organic Synthesis, E. Negishi, Ed., J. Wiley \& Sons, New York, 2002, Sect. VI.2.3, 2455-2471.

328. Intramolecular Acylpalladation Reactions with Alkenes, Alkynes, and Related Unsaturated Compounds.

C. Copéret and E. Negishi, In The Handbook of Organopalladium Chemistry for Organic Synthesis, E. Negishi, Ed., J. Wiley \& Sons, New York, 2002, Sect. VI.4.1.1, 2519-2552.

329. Palladium-Catalyzed Heterogeneous Hydrogenation.

A. O. King, R. D. Larsen, and E. Negishi, In The Handbook of Organopalladium Chemistry for Organic Synthesis, E. Negishi, Ed., J. Wiley \& Sons, New York, 2002, Sect. VII.2.1, 2719-2758. 
330. Palladium-Catalyzed Isomerization of Alkenes, Alkynes, and Related Compounds without Skeletal Rearrangements.

E. Negishi, In The Handbook of Organopalladium Chemistry for Organic Synthesis, E. Negishi, Ed., J. Wiley \& Sons, New York, 2002, Sect. VII.3, 2783-2788

321. Palladium-Catalyzed Cross-Coupling Involving $\beta$-Hetero-Substituted Compounds Other than Enolates.

E. Negishi and A. Alimardanov, In The Handbook of Organopalladium Chemistry for Organic Synthesis, E. Negishi, Ed., J. Wiley \& Sons, New York, 2002, Sect. III.2.14.2, 721-766.

322. Palladium-Catalyzed Conjugate Substitution

E. Negishi and Y. Dumond, In The Handbook of Organopalladium Chemistry for Organic Synthesis, E. Negishi, Ed., J. Wiley \& Sons, New York, 2002, Sect. III.2.15, 767-789.

323. Synthesis of Natural Products via Palladium-Catalyzed Cross-Coupling.

A. Tan and E. Negishi, In The Handbook of Organopalladium Chemistry for Organic Synthesis, E. Negishi, Ed., J. Wiley \& Sons, New York, 2002, Sect. III.2.18, 863-942.

324. Palladium-Catalyzed Tandem and Cascade Carbopalladation of Alkynes and 1,1-Disubstituted Alkenes Terminated by Carbonylative Reactions.

E. Negishi and C. Copéret, In The Handbook of Organopalladium Chemistry for Organic Synthesis, E. Negishi, Ed., J. Wiley \& Sons, New York, 2002, Sect. IV.3.3, 1431-1448.

325. Palladium-Catalyzed Allylation and Related Substitution Reactions of Enolates and Related Derivatives of "Ordinary" Ketones, and Aldehydes, and Other Carbonyl Compounds.

E. Negishi S. Y. Liou, In The Handbook of Organopalladium Chemistry for Organic Synthesis, E. Negishi, Ed., J. Wiley \& Sons, New York, 2002, Sect. V.2.1.4, 1769-1793.

326. Synthesis of Natural Products via Nucleophilic Attack on $\pi$-Ligands of Palladium-Alkene, Palladium-Alkyne, and Related $\pi$-Complexes.

C. Xu and E. Negishi, In The Handbook of Organopalladium Chemistry for Organic Synthesis, E. Negishi, Ed., J. Wiley \& Sons, New York, 2002, Sect. V.3.6, 2289-2305.

327. Reactions of Acylpalladium Derivatives with Enolates and Related Amphiphilic Reagents. 
E. Negishi and H. Makabe, In The Handbook of Organopalladium Chemistry for Organic Synthesis, E. Negishi, Ed., J. Wiley \& Sons, New York, 2002, Sect. VI.2.3, 2455-2471.

328. Intramolecular Acylpalladation Reactions with Alkenes, Alkynes, and Related Unsaturated Compounds.

C. Copéret and E. Negishi, In The Handbook of Organopalladium Chemistry for Organic Synthesis, E. Negishi, Ed., J. Wiley \& Sons, New York, 2002, Sect. VI.4.1.1, 2519-2552.

329. Palladium-Catalyzed Heterogeneous Hydrogenation.

A. O. King, R. D. Larsen, and E. Negishi, In The Handbook of Organopalladium Chemistry for Organic Synthesis, E. Negishi, Ed., J. Wiley \& Sons, New York, 2002, Sect. VII.2.1, 2719-2758.

330. Palladium-Catalyzed Isomerization of Alkenes, Alkynes, and Related Compounds without Skeletal Rearrangements.

E. Negishi, In The Handbook of Organopalladium Chemistry for Organic Synthesis, E. Negishi, Ed., J. Wiley \& Sons, New York, 2002, Sect. VII.3, 2783-2788

331. Palladium-Catalyzed Hydrometallation.

H. Makabe and E. Negishi, In The Handbook of Organopalladium Chemistry for Organic Synthesis, E. Negishi, Ed., J. Wiley \& Sons, New York, 2002, Sect. VII.4, 2789-2823.

332. Other Palladium-Catalyzed or -Promoted Oxidation Reactions via 1,2- or 1,4-Elimination.

Y. Fujiwara and E. Negishi, In The Handbook of Organopalladium Chemistry for Organic Synthesis, E. Negishi, Ed., J. Wiley \& Sons, New York, 2002, Sect. VIII.3.3, 2895-2903.

333. Other Miscellaneous Palladium-Catalyzed or -Promoted Oxidation Reactions.

E. Negishi, In The Handbook of Organopalladium Chemistry for Organic Synthesis, E. Negishi, Ed., J. Wiley \& Sons, New York, 2002, Sect. VIII.4, 2905-2912.

334. Palladium-Catalyzed Carbon Skeletal Rearrangements Other than [3,3] Rearrangements.

E. Negishi, In The Handbook of Organopalladium Chemistry for Organic Synthesis, E. Negishi, Ed., J. Wiley \& Sons, New York, 2002, Sect. IX.2.1.2, 2935-2938.

335. Organometallic Complexes of Zirconium and Hafnium. 
E. Negishi and T. Takahashi, Houben-Weyl, Science of Synthesis, Vol. 2, T. Imamoto, Ed., Thieme, 2002, Chap. 2.11, 681-848.

336. (E)-1-Bromo-4-trimethylsilyl-1-buten-3-yne and (E)-1-Bromo-4-(tert-butyldimethylsilyl)-1-buten3-yne.

E. Negishi and F. Zeng, Encyclopedia of Reagents for Organic Synthesis, L. A. Paquette, Ed., John Wiley \& Sons, Inc., New York, 2002.

337. Highly Satisfactory Alkynylation of Alkenyl Halides via Pd-Catalyzed Cross-Coupling with Alkynylzincs and Its Critical Comparison with the Sonogashira Alkynylation.

E. Negishi, M. Qian, F. Zeng, L. Anastasia, and D. Babinski, Org. Lett., 2003, 5, 1597-1600.

338. Strictly "Pair"-Selective and Economical Synthesis of Conjugated Diynes via Pd-Catalyzed Reaction of Terminal Alkynes with 1,1-Dichloroethylene, Elimination with LDA, and Subsequent Transformations

M. Qian and E. Negishi, Org. Process. Res. Dev., 2003, 7, 412-417.

339. Highly Selective Synthesis of (E)-3-Methyl-1-trialkylsilyl-3-en-1-ynes via trans-Selective Alkynylation Catalyzed by $\mathrm{Cl}_{2} \mathrm{Pd}(\mathrm{DPEphos})$ and Stereospecific Methylation with Methylzincs Catalyzed by $\operatorname{Pd}\left({ }^{t} \mathrm{Bu}_{3} \mathrm{P}\right)_{2}$.

J. Shi, X. Zeng, and E. Negishi, Org. Lett., 2003, 5, 1825-1828.

340. Palladium-Catalyzed Alkynylation.

E. Negishi and L. Anastasia, Chem. Rev., 2003, 103, 1979-2017

341. Clean Inversion of Configuration in the Pd-Catalyzed Cross-Coupling of 2-Bromo-1,3-dienes. X. Zeng, Q. Hu, M. Qian, and E. Negishi, J. Am. Chem. Soc., 2003, 125, 13636-13637.

342. Pd-Catalyzed Selective Tandem Arylation of 1,1-Dihalo-1-alkenes with Aryl- and Alkylzinc Derivatives to Produce $\alpha$-Alkyl-substituted Styrene Derivatives.

J. Shi and E. Negishi, J. Organomet. Chem., 2003, 687, 518-524.

343. Highly Stereoselective Synthesis of (1E)-2-Methyl-1,3-dienes by Palladium-Catalyzed trans-Selective Cross-Coupling of 1,1-Dibromo-1-alkenes with Alkenylzinc Reagents 
X. Zeng, M. Qian, Q. Hu, and E. Negishi, Angew. Chem. Int. Ed., 2004, 43, 2259-2263.

344. A New, Efficient, and General Route to Reduced Polypropionates via Zr-Catalyzed Asymmetric $\mathrm{C}-\mathrm{C}$ Bond Formation.

E. Negishi, Z. Tan, B. Liang, and T. Novak, Proc. Natl. Acad. Sci. USA, 2004, 101, 5782-5787.

345. Disasteroselective, Enantioselective, and Regioselective Carboalumination Reactions Catalyzed by Zirconocene Derivatives.

E. Negishi and Z. Tan, Topics in Organometallic Chemistry, T. Takahashi, Ed., Springer, 2004, Chap. 4, 139-176.

346. Zr-Promoted "Pair"-selective and Regioselective Synthesis of Penta-substituted Benzene Derivatives.

Y. R. Dumond and E. Negishi, Tetrahedron, 2004, 60, 1345-1352

347. An Efficient and General Method for the Synthesis of $\alpha, \omega$-Difunctional Reduced Polypropionates by Zr-catalyzed Asymmetric Carboalumination: Synthesis of the Scyphostatin Sidechain.

Z. Tan and E. Negishi, Agnew. Chem. Int. Ed., 2004, 43, 2911-2914.

348. Efficient and Selective Synthesis of Siphonarienolone and Related Reduced Polypropionates via Zr-Catalyzed Asymmetric Carboalumination.

M. Magnin-Lachaux, Z. Tan, B. Liang, and E. Negishi, Org. Lett., 2004, 6, 1425-1427.

349. Use of $\mathrm{InCl}_{3}$ as a Cocatalyst and a $\mathrm{Cl}_{2} \mathrm{Pd}(\mathrm{DPEphos})-\mathrm{P}(2-\mathrm{Furyl})_{3}$ Catalyst System for One-Pot Hydrometalation-Cross-Coupling and Carbometalation-Cross-Coupling Tandem Processes.

M. Qian, Z. Huang, and E. Negishi, Org. Lett., 2004, 6, 1531-1534.

350. Palladium- or Nickel-Catalyzed Cross-Coupling with Organometals Containing Zinc, Aluminum, and Zirconium: The Negishi Coupling

E. Negishi, X. Zeng, Z. Tan, M. Qian, Q. Hu, and Z. Huang, Metal-Catalyzed $C-C$ and $C-N$ Coupling Reactions, de A. Meijere and F. Diederich, Eds., Wiley-VCH, 2004, Chap. 15, p. 815 889.

351. Efficient and Selective Synthesis of 6,7-Dehydrostipiamide via Zr-Catalyzed Asymmetric 
Carboalumination and Pd-Catalyzed Cross-Coupling of Organozincs.

X. Zeng, F. Zeng, and E. Negishi, Org. Lett., 2004, 6, 3245-3248.

352. All-Catalytic, Efficient, and Asymmetric Synthesis of $\alpha, \omega$-Diheterofunctional Reduced Polypropionates via "One-Pot" Zr-Catalyzed Asymmetric Carboalumination-Pd-Catalyzed Cross-Coupling Tandem Process.

T. Novak, Z. Tan, B. Liang, and E. Negishi, J. Am. Chem. Soc., 2005, 127, 2838-2839.

353. Palladium-Catalyzed Cross-Coupling Reaction of Alkynylzincs with Benzylic Electrophiles.

M. Qian and E. Negishi, Tetrahedron Lett., 2005, 46, 2927-2930.

354. Palladium-Catalyzed Cross-Coupling Reactions with Zinc, Boron, and Indium Exhibiting High Turnover Numbers (TONs): Use of Bidentate Phosphines and Other Critical Factors in Achieving High TONs.

Z. Huang, M. Qian, D. T. Babinski, and E. Negishi, Organometallics, 2005, 24, 475-478.

355. A Quarter of a Century of Explorations in Organozirconium Chemistry.

E. Negishi, Dalton Trans., 2005, 827-848.

356. Di- $n$-butylbis $\left(\eta^{5}\right.$-cyclopentadienyl)zirconium.

E. Negishi and T. Novak, Electronic Encyclopedia of Reagents for Organic Synthesis, L. A. Paquette, Ed., John Wiley \& Sons, Inc., New York, 2005.

357. Palladium-Catalyzed Cross-Coupling of Alkynylzincs with Allylic Electrophiles: An Efficient and Selective Synthesis of Stereo- and Regio-Defined 1,4-Enynes.

M. Qian and E. Negishi, Synlett, 2005, 1789-1793.

358. Palladium-Catalyzed trans-Selective Alkynylation-Alkylation Tandem Reaction of 1,1-Dihalo-1alkenes for the Syntehsis of (E)-3-Alkyl-1-trialkylsilyl-3-en-1-ynes.

E. Negishi, J. Shi, and X. Zeng, Tetrahedron, 2005, 61, 9886-9895.

359. Palladium-Catalyzed Alkenylation via Negishi Coupling.

E. Negishi, Q. Hu, Z. Huang, M. Qian, and G. Wang, Aldrichim. Acta, 2005, 38, 71-88. 
360. Palladium-Catalyzed Cyclization via Carbopalladation and Acylpalladation.

E. Negishi, G. Wang, and G. Zhu, Topics in Organometallic Chemistry 19. Metal Catalyzed Cascade Reactions, T. J. J. Müller, Ed., Springer, Heidelberg, 2006, Vol. 19, pp. 1-48.

361. Widely Applicable Pd-Catalyzed trans-Selective Monoalkylation of Unactivated 1,1-Dichloro-1alkenes and Pd-Catalyzed Second Substitution for the Selective Synthesis of $(E)$ - or (Z)Trisubstituted Alkenes

Z. Tan and E. Negishi, Angew. Chem. Int. Ed., 2006, 45, 762-765.

362. Catalytic, Efficient, and syn-Selective Construction of Deoxypolypropionates and Other Chiral Compounds via Zr-Catalyzed Asymmetric Carboalumination of Allyl Alcohol.

B. Liang, T. Novak, Z. Tan, and E. Negishi, J. Am. Chem. Soc., 2006, 128, 2770-2771.

363. Zirconium-Catalyzed Asymmetric Carboalumination (ZACA Reaction) of 1,4-Dienes.

Z. Tan, B. Liang, S. Huo, J. Shi, and E. Negishi, Tetrahedron: Asymmetry, 2006, 17, 512-515.

364. Highly Stereoselective Synthesis of the Side-Chains of Mycolactones A and B Featuring Stepwise Double Substitutions of 1,1-Dibromo-1-alkenes.

N. Yin, G. Wang, M. Qian, and E. Negishi, Angew. Chem. Int. Ed., 2006, 45, 2916-2920.

365. Palladium- or Nickel-Catalyzed Cross-Coupling with Organozincs and Related Organometals. E. Negishi, Q. Hu, Z. Huang, G. Wang, and N. Yin, The Chemistry of Organozinc Compounds, Z. Rappoport and I. Marek, Eds., John Wiley \& Sons, Ltd., Chichester, England, 2006, Chap. 11, 453-553.

366. Selective Synthesis of Epolactaene Featuring Efficient Construction of Methyl (Z)-2-lodo-2butenoate and $(2 R, 3 S, 4 S)$-2-Trimethylsilyl-2,3-epoxy-4-methyl- $\gamma$-butyrolactone.

Z. Tan and E. Negishi, Org. Lett., 2006, 8, 2783-2785.

367. A Convenient and Genuine Equivalent to $\mathrm{HZrCp}{ }_{2} \mathrm{Cl}$ Generated in situ from $\mathrm{ZrCp}_{2} \mathrm{Cl}_{2}-\mathrm{DlBAL}-\mathrm{H}$. Z. Huang and E. Negishi, Org. Lett., 2006, 8, 3675-3678.

368. Highly Efficient and Selective Synthesis of Conjugated Triynes and Higher Oligoynes of Biological and Materials Chemical Interest via Palladium-Catalyzed Alkynyl-Alkenyl Coupling. 
E. Métay, Q. Hu, and E. Negishi, Org. Lett., 2006, 8, 5773-5776.

369. ZACA Reaction: Zr-Catalyzed Asymmetric Carboalumination of Alkenes.

E. Negishi, B. Liang, T. Novak, and Z. Tan, Asymmetric Synthesis-The Essentials, S. Bräse and M. Christmann, Eds., Wiley-VCH, Weinheim, 2007, 126-130.

370. $\mathrm{C}-\mathrm{C}$ Bond Formation (Part 1) by Addition Reactions: Through Carbometallation Mediated by Group 4-7 Metals

E. Negishi and T. Novak, Comprehensive Organometallic Chemistry III, Vol. 10, I. Ojima, Ed., Elsevier, Oxford, 2007, Chap. 10.06, 251-297.

371. Transition Metal-Catalyzed Organometallic Reactions that Have Revolutionized Organic Synthesis (Vol. 80 Commemorative Accounts).

E. Negishi, Bull. Chem. Soc. Jpn., 2007, 80, 233-257.

372. Zirconium-Catalyzed Asymmetric Carboaluminumination of Alkenes: ZACA-Lipase-Catalyzed Acetylation Synergy.

Z. Huang, Z. Tan, T. Novak, G. Zhu, and E. Negishi, Adv. Synth. Catal., 2007, 349, 539-545.

373. Fully Reagent-Controlled Asymmetric Synthesis of (-)-Spongidepsin via the Zr-Catalyzed Asymmetric Carboalumination of Alkenes (ZACA Reaction).

Z. Zhu and E. Negishi, Org. Lett., 2007, 9, 2771-2774.

374. Zirconicum-Catalyzed Methylalumination of Heterosubstituted Arylethynes. Factors Affecing the Regio-, Stereo-, and Chemoselectivities.

G. Wang, G. Zhu, and E. Negishi, J. Organomet. Chem., 2007, 692, 4731-4736.

375. Highly Stereo- and Regioselective Synthesis of (Z)-Trisubstituted Alkenes via 1-Bromo-1-alkyne Hydroboration-Migratory Insertion-Zn-Promoted Iodinolysis and Pd-Catalyzed Organozinc Cross-Coupling.

Z. Huang and E. Negishi, J. Am. Chem. Soc., 2007, 129, 14788-14792.

376. Negishi Coupling - Expedient Formation of Biphenyls on the Periphery of Inorganic/ Organometallic Diruthenium Species. 
L. Zhang, Z. Huang, W.-Z. Chen, E. Negishi, P. E. Fanwick, J. B. Updegraff, J. D. Protasiewicz, and T. Ren, Organometallics, 2007, 26, 6526-6528.

377. 1,4-Pentenynes as a Five-Carbon Synthon for Efficient and Selective Syntheses of Natural Products Containing 2,4-Dimethyl-1-penten-1,5-ylidene and Related Moieties by Means of Zr-Catalyzed Carboalumination of Alkynes and Alkenes.

G. Zhu and E. Negishi, Chem. Eur. J., 2008, 14, 311-318.

378. Highly Efficient Asymmetric Synthesis of Fluvirucinine $A_{1}$ via Zr-Catalyzed Asymmetric Carboalumination of Alkenes (ZACA)-Lipase-Catalyzed Acetylation Tandem Process.

B. Liang and E. Negishi, Org. Lett., 2008, 10, 193-195.

379. Efficient and Selective Synthesis of $(S, R, R, S, R, S)-4,6,8,10,16,18$-Hexamethyldocosane via Zr-Catalyzed Asymmetric Carboalumination of Alkenes (ZACA) Reaction.

G. Zhu, B. Liang, and E. Negishi, Org. Lett., 2008, 10, 1099-1101.

380. Recent Advances in the Efficient and Selective Synthesis of Di-, Tri-, and Tetrasubstituted Alkenes via Pd-Catalyzed Alkenylation-Carbonyl Olefination Synergy.

E. Negishi, Z. Huang, G. Wang, S. Mohan, C. Wang, and H. Hattori, Acc. Chem. Res., 2008, 41, 1474-1485.

381. Efficient and Selective Syntheses of (all-E)- and $(6 E, 10 Z)-2^{\prime}-O-M e t h y l m y x a l a m i d e s ~ D$ via Pd-Catalyzed Alkenylation-Carbonyl Olefination Synergy.

G. Wang, Z. Huang, and E. Negishi, Org. Lett., 2008, 10, 3223-3226

382. Dichlorbis(triphenylphosphine)palladium(II).

E. Negishi and S. Mohan, Encylopedia of Reagents for Organic Synthesis, L. A. Paquette, Ed., John Wiley \& Sons, Inc. Hoboken, New Jersey, 2008.

383. Efficient and Stereoselective Synthesis of Yellow Scale Pheromone via Alkyne Haloboration, Zr-Catalyzed Asymmetric Carboalumination of Alkenes (ZACA Reaction), and Pd-Catalyzed Tandem Negishi Coupling.

Z. Xu, and E. Negishi, Org. Lett., 2008, 10, 4311-4314. 
384. $\mathrm{AlCl}_{3}$-Promoted Facile $E$-to- $Z$ Isomerization Route to (Z)-2-Methyl-1-buten-1,4-ylidene Synthons for Highly Efficient and Selective (Z)-Isoprenoid Synthesis.

G. Wang and E. Negishi, Eur. J. Org. Chem., 2009, 11, 1679-1682.

Note: Invited contribution to a special issue dedicated to Alain Krief.

385. Highly Stereoselective and Efficient Synthesis of $\omega$-Heterofunctional Di- and Trienoic Esters for Horner-Wadsworth-Emmons Reaction via Alkyne Hydrozirconation and Pd-Catalyzed Alkenylation.

G. Wang, Z. Huang, and E. Negishi, Tetrahedron Lett., 2009, 50, 3220-3223.

Note: Invited contribution to the 50th Anniversary Issue.

386. Highly Regio- and Stereoselective Synthesis of Z-Trisubstituted Alkenes via Propyne Bromoboration and Tandem Pd-Catalyzed Cross-Coupling.

C. Wang, T. Tobrman, Z. Xu, and E. Negishi, Org. Lett., 2009, 11, 4092-4095.

387. Synthesis of 1,3-Dienes by Metal-Mediated Coupling Reactions.

E. Negishi and G. Wang, Science of Synthesis, Vol. 46, V. Rawal and S. Kozmin, Eds, Thieme, Stuttgart, 2009, Chap. 46.6, 239-252.

388. Synthesis of Alkenes from Alkynes by Hydrometallation and Subsequent Coupling Reactions.

E. Negishi and G. Wang, Science of Synthesis, Vol. 47, E. N. Jacobsen and A. de Meijere, Eds., Thieme, Stuttgart, 2010, Chap. 47.1.5.3, 909-970.

389. Synthesis of Alkenes from Alkynes by Carbometallation and Subsequent Coupling Reactions.

E. Negishi and G. Wang, Science of Synthesis, Vol. 47, E. N. Jacobsen and A. de Meijere, Eds., Thieme, Stuttgart, 2010, Chap. 47.1.5.4, 971-1016.

390. Alkyne Elementometalation-Pd-Catalyzed Cross-Coupling. Towards Synthesis of Various Types of Alkenes in High Yields, Efficiently, Selectively, Economically, and Safely - "Green" Way.

E. Negishi, G. Wang, H. Rao, and Z. Xu, J. Org. Chem. (Perspective), 2010, 75, 3151-3182.

391. Arylethyne Bromoboration-Negishi Coupling Route to E- or Z-Aryl-Substituted Trisubstituted Alkenes of $\geq 98 \%$ Isomeric Purity. New Horizon in the Highly Selective Synthesis of Trisubstituted Alkenes. 
C. Wang, Z. Xu, T. Tobrman, and E. Negishi, Adv. Synth. Catal., 2010, 352, 627-631.

392. Total Synthesis of (+)-Scyphostatin Featuring an Enantioselective and Highly Efficient Route to the Side-Chain via Zr-Catalyzed Asymmetric Carboalumination of Alkenes (ZACA).

E. Pitsinos, N. Athinaios, Z. Xu, G. Wang, and E. Negishi, Chem. Commun., 2010, 46, 2200-2202.

Note: This article is part of a ChemComm Catalysis in Organic Synthesis web-theme issue.

393. Highly ( $\geq 98 \%$ ) Selective Trisubstuted Alkene Synthesis of Wide Applicabilitry via FluoridePromoted Pd-Catalyzed Cross-Coupling of Alkenylboranes.

E. Negishi, T. Tobrman, H. Rao, S. Xu, and C. T. Lee, Isr. J. Chem., 2010, 50, 696-701.

Note: An invited publication for a special issue of Isr. J. Chem.

394. Highly Stereoselective Total Synthesis of Fully Hydroxy-Protected Mycolactones A \& B and Their Stereoisomerization upon Deprotection.

G. Wang, N. Yin, and E. Negishi, Chem. Eur. J., 2011, 17, 4118-4130.

395. Discovery of ZACA Reaction: Zr-Catalyzed Asymmetric Carboalumination of Alkenes.

E. Negishi, ARKIVOC, 2011, Part (viii), 34-53.

Note: An invited publication for a special issue dedicated to U. M. Dzhemilev.

396. Highly ( $\geq 98 \%$ ) Selective Synthesis of Conjugated Dienoic and Trienoic Esters via Alkyne Elementometalation - Pd-Catalyzed Cross-Coupling.

G. Wang, S. Mohan, and E. Negishi, Proc. Natl. Acad. Sci. USA, 2011, 108, 11344-11349.

397. Highly ( $\geq 98 \%$ ) Stereo- and Regioselective Trisubstituted Alkene Synthesis of Wide Applicability via 1-Halo-1-alkyne Hydroboration - Tandem Negishi-Suzuki Coupling or Organoborate Migratory Insertion.

S. Xu, C. T. Lee, H. Rao, and E. Negishi, Adv. Synth. Cat., 2011, 353, 2981-2987.

398. Highly Efficient and Selective ( $\geq 98 \%$ ) Synthesis of Amphotericin B C19-C37 Fragment via Alkyne Hydrometalation - Pd-Catalyzed Alkenylation.

G. Wang, Q. Hu, F. Zeng, and E. Negishi, submitted.

399. Synthesis of Feebly Chiral 2-Branched 1-Alkanols of Ultra-High Enantiomeric Purity (>99\% ee) 
via ZACA Reaction (Zr-Catalyzed Asymmetric Carboalumination of Alkenes)

S. Xu, C. T. Lee, G. Wang, and E. Negishi, Proc. Natl. Acad. Sci. USA, manuscript in preparation.

400. Magical Power of Transition Metals: Past, Present, and Future (Nobel Lecture).

E. Negishi, Angew. Chem. Int. Ed., 2011, 50, 6738-6764. 


\section{MISCELLANEOUS PUBLICATIONS}

MISC-1 (Book review) Organoborane Chemistry, Onak, T.

Academic Press, New York, 1975

E. Negishi, Science, 1976, 192, 134.

MISC-2 Scientific Contributions of Professor Herbert C. Brown

E. Negishi, J. Organomet. Chem., 1978, 156, xi-xv.

MISC-3 The 1979 Nobel Prize for Chemistry

E. Vedejs, J. H. Brewster, and E. Negishi, Science, 1980, 207, 42-45.

MISC-4 (Book review) Catalysis in Organic Synthesis, Jones, W. H., Ed., Academic Press, New York, 1980, 314 pp.

E. Negishi, J. Organomet. Chem., 1980, 199, C50.

MISC-5 Profile of Professor H. C. Brown

E. Negishi, Heterocycles, 1982, 18, 7-11.

MISC-6 (Book review) Asymmetric Reactions and Processes in Chemistry, Eliel, E. L.; Otsuka, S., Eds., ACS Symposium Series No. 185, American Chemical Society, Washington, D. C., 1982, $300 \mathrm{pp}$.

E. Negishi, Organometallics, 1982, 1, 1556.

MISC-7 (Book review) Organomercury Compounds in Organic Synthesis. vol. 22. Reactivity and Structure Concepts in Organic Chemistry, Larock, R. C., Springer-Verlag, Heidelberg, 1985, $432 \mathrm{pp}$.

E. Negishi, J. Am. Chem. Soc., 1986, 108, 7886.

MISC-8 A Tribute to Herbert C. Brown

E. Negishi and U. Racherla, Heteroatom Chem., 1992, 3, 201-208.

MISC-9 On American Culture (in Japanese)

E. Negishi, Medchem. News (The Pharmaceutical Society of Japan, Division of Medicinal 
Chemistry), 1995, 5, 75-77.

MISC-10 My Way - Pursuit of Happiness with Eternal Optimism (in Japanese).

E. Negishi, My First 60 Years (in Japanese), T. Takahashi, Ed., 1996, 1-6.

MISC-11 Conditions for Discovery (in Japanese).

E. Negishi, J. Synth. Org. Chem. Jpn., 1996, 56, 1.

MISC-12 A Profile of Professor Richard F. Heck: Discovery of the Heck Reaction.

E. Negishi, J. Organomet. Chem., 1999, 578, R15

MISC-13 Historical Background of Organopalladium Chemistry.

E. Negishi, In The Handbook of Organopalladium Chemistry for Organic Synthesis, E. Negishi, Ed., J. Wiley \& Sons, New York, 2002, Sect. I.1, 1 - 15.

MISC-14 Background for Chapter II.

E. Negishi, In The Handbook of Organopalladium Chemistry for Organic Synthesis, E. Negishi, Ed., J. Wiley \& Sons, New York, 2002, Sect. II.1, 37 - 40.

MISC-15 Metallic Pd and Its Mixtures.

E. Negishi, In The Handbook of Organopalladium Chemistry for Organic Synthesis, E. Negishi, Ed., J. Wiley \& Sons, New York, 2002, Sect. II.2.1, 41 - 42.

MISC-16 Palladium Complexes Containing Halogen and Oxygen Ligands.

E. Negishi, In The Handbook of Organopalladium Chemistry for Organic Synthesis, E. Negishi, Ed., J. Wiley \& Sons, New York, 2002, Sect. II.2.2, 43 - 45.

MISC-17 $\operatorname{Pd}(0)$ and $\operatorname{Pd}(\mathrm{II})$ Complexes Containing Phosphorus and Other Group 15 Atom Ligands.

D. Choueiry and E. Negishi, In The Handbook of Organopalladium Chemistry for Organic Synthesis, E. Negishi, Ed., J. Wiley \& Sons, New York, 2002, Sect. II.2.3, 47-65.

MISC-18 Background for Chapter III.

E. Negishi, In The Handbook of Organopalladium Chemistry for Organic Synthesis, E. Negishi, Ed., J. Wiley \& Sons, New York, 2002, Sect. III.1, 215-227. 
MISC-19 Palladium-Catalyzed Carbon-Carbon Cross Coupling: Overview of the Negishi Protocol with Zn, Al, Zr, and Related Metals.

E. Negishi, In The Handbook of Organopalladium Chemistry for Organic Synthesis, E. Negishi, Ed., J. Wiley \& Sons, New York, 2002, Sect. III.2.1, 229-247.

MISC-20 Background for Chapter V.

E. Negishi, E., In The Handbook of Organopalladium Chemistry for Organic Synthesis, E. Negishi, Ed., J. Wiley \& Sons, New York, 2002, Sect. V.1, 1663-1667.

MISC-21 Background for Chapter VI.

E. Negishi, In The Handbook of Organopalladium Chemistry for Organic Synthesis, E. Negishi, Ed., J. Wiley \& Sons, New York, 2002, Sect. VI.1, 2309- 2311.

MISC-22 Background for Chapter VII.

E. Negishi, In The Handbook of Organopalladium Chemistry for Organic Synthesis, E. Negishi, Ed., J. Wiley \& Sons, New York, 2002, Sect. VII.1, 2715-2718.

MISC-23 Background for Chapter VIII.

E. Negishi, In The Handbook of Organopalladium Chemistry for Organic Synthesis, E. Negishi, Ed., J. Wiley \& Sons, New York, 2002, Sect. VIII.1, 2853-2857.

MISC-24 Background for Chapter IX.

E. Negishi, In The Handbook of Organopalladium Chemistry for Organic Synthesis, E. Negishi, Ed., J. Wiley \& Sons, New York, 2002, Sect. IX.1, 2915-2917.

MISC-25 General Guidelines on References Pertaining to Palladium and Organopalladium Chemistry. E. Negishi, In The Handbook of Organopalladium Chemistry for Organic Synthesis, E. Negishi, Ed., J. Wiley \& Sons, New York, 2002, Sect. R.1, 3129-3135.

MISC-26 Books on Organotransition Metal and Organopalladium Chemistry.

E. Negishi, In The Handbook of Organopalladium Chemistry for Organic Synthesis, E. Negishi, Ed., J. Wiley \& Sons, New York, 2002, Sect. R.2, 3137-3138.

MISC-27 Reviews and Accounts on Organopalladium Chemistry. 
E. Negishi and F. Liu, In The Handbook of Organopalladium Chemistry for Organic Synthesis, E. Negishi, Ed., J. Wiley \& Sons, New York, 2002, Sect. R.3, 3139- 3172.

MISC-28 Pd- and Zr-Catalyzed $\mathrm{C}-\mathrm{C}$ and $\mathrm{C}-\mathrm{X}$ Bond Formation.

E. Negishi, My Favorite Organic Synthesis, K. Tatsuta and T. Fukuyama, Eds., Soc. Synth. Org. Chem. Jpn., (Kagaku-Dojin Inc.), 2002, 136-137.

MISC-29 Research Systems at American Universities and Models for Research System at Hokkaido University.

E. Negishi, Special Report to the President of Hokkaido University, Sapporo, Japan, 2002, $45 \mathrm{pp}$.

MISC-30 Goma-ae with White Sesame and Goma-yagoshi with Black Sesame.

S. Negishi and E. Negishi, What's Cooking in Chemistry? How Leading Chemists Succeed in the Kitchen, H. D. Bell, et al., Eds., Wiley-VCH, Weinheim, 2003, 232 pp.

MISC-31 Organometallic Chemistry for Organic Synthesis. Forty Years of Continuous Excitement (in Japanese).

E. Negishi, "Moments of Excitement for Chemists", (in Japanese), J. Tsuji, Ed. Kagaku Dojin, 2006, 86-90.

MISC-32 ZACA Reaction: Zr-Catalyzed Asymmetric Carboalumination of Alkenes (in Japanese).

E. Negishi, Wako Jiho, 2007, 75, 2-8.

MISC-33 Herbert Charles Brown (May 22, 1912-December 19, 2004).

E. Negishi, Nat'l. Acad. Sci. USA, 2008, 1-15 pp.

MISC-34 Yume o Mochitsuzukeyo (in Japanese).

("Pursue Your Lofty Dreams with Eternal Optimism")

E. Negishi, Kyodo Press, 2010, December 10, 181 pp.

MISC-35 Research Philosophy of Ei-ichi Negishi, Ph.D., a 2010 Nobel Prize Winner in Chemistry (Based on an interview, March 6, 2011, in Japanese)

E. Negishi, Chemistry Today (Japanese), 2011, June, p. 20-24. 
MISC-36 Magical Power of Transition Metal Catalysts (in Japanese)

E. Negishi, Gakushi-kai Kaiho, 2011, No. 890, p. 72-84.

MISC-37 Magical Power of $d$-Block Transition Metals: Past, Present, and Future. Special Lecture at the Annual Assembly of the Science Council of Japan, Tokyo, April 5, 2011 (in Japanese). E. Negishi.

MISC-38 Herbert C. Brown: My Life-time Mentor (Onshi o kataru, in Japanese).

E. Negishi, U Seven (Gakushi-kai Kaiho), 2011, 38, 54-57.

MISC-39 Let's Meet in the Hall: Guest - Ei-ichi Negishi, a 2010 Nobel Prize Winner in Chemistry (Based on an interview in Japanese).

E. Negishi, Let's Meet in the Hall, 2011, November 5, p. 64-68.

MISC-40 EI-ICHI NEGISHI (Autobiographical Part of Nobel Lecture (EN No. 400).

E. Negishi, Angew. Chem. Int. Ed., 2011, 50, 6738-6764.

MISC-41 Pursue Your Lofty Dreams with Eternal Optimism (based on a lecture in Japanese presented on November 24, 2010 at Shonan High School).

E. Negishi, "Shonan PTA Koho" (Japanese), 2011, No. 86, p. 2-3.

MISC-42 Research in Synthetic Organic Chemistry That Has Presented Me Continuous Excitement and Satisfaction (in Japanese).

E. Negishi, Chemistry (publication in Japanese), 2011, 66, 22-25.

Note: See also an accompanying memoire by T. Takahashi, p. 26-29.

MISC-43 Put Yourself in the Environment that Best Fits You (in Japanese).

E. Negishi, “Inside Todai (Japanese), Tokyo Daigaku Shimbun-sha, 2011, p. 4-9.

MISC-44 Catalysis with d-Block Transition Metals for Green Organic Synthesis and a Sustainable World.

E. Negishi, J. Synth. Org. Chem., Jpn (in English), 2011, 69, p. 1201.

MISC-45 Building Sustainable $21^{\text {st }}$ Century (based on an interview in Japanese). 
E. Negishi, Kajima, 2011, No. 628, p. 30.

MISC-46 Building New Japan through Scientific and Technological Innovations (in Japanese).

M. Nakamura and E. Negishi, JST News, 2012, p. 6-9.

MISC-47 Conditions for Discovery (in Japanese) in Yumi’s Yumiyori-na Hanashi Chuo-Koron Shinsha, to be published. 


\section{PATENTS}

1. Highly Elastic Linear Ployurethanes, E. Negishi, A. Horike, and Y. Ishizuka, (Teijin Ltd.) Brit. Patent 1,116,116,6, 1968 (Applied Sept. 2, 1966). cf. Chem. Abstr., 69 P28544d (1968).

2. Linear Elastic Polymer, Y. Taneda and E. Negishi, (Teijin Ltd.), Japan Patent 68 13,999, June 13, 1968 (Applied Oct. 3, 1964). cf. Chem. Abstr., 69, P94672d (1968).

3. Polyurethane Elastomers, E. Negishi, A. Horike, and Y. Ishizuka, (Teijin Ltd.) Japan Patent 69 06,840, March 25, 1969 (Applied Nov. 2, 1964). cf. Chem. Abstr., 71, P22833s (1969).

4. Polyurethane Elastomer Whiteness Improvement, E. Negishi, M. Yamamoto, and A. Horike, (Teijin Ltd.), Japan Patent 70 0,592, January 9, 1970 (Applied April 7, 1966). cf. Chem. Abstr., 73, 4751a (1970).

5. Chiral Organoalanes and Their Organic Derivatives via Zirconium-Catalyzed Asymmetric Carboalumination of Terminal Alkenes, E. Negishi and D. Y. Kondakov, (Purdue Research Foundation) US Patent 6,002,037, Dec. 14, 1999 (Applied Oct. 14, 1997). 